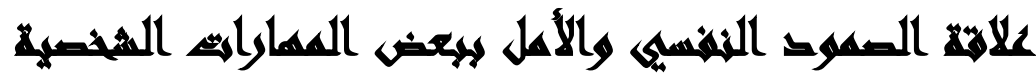

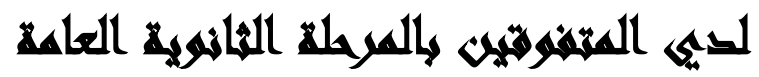

\section{[1 1 ]}

طه عبد الرحمن محمد|(')- أحمد مصطفى العتيق (')- الفرحاتى السيد محمود(r)

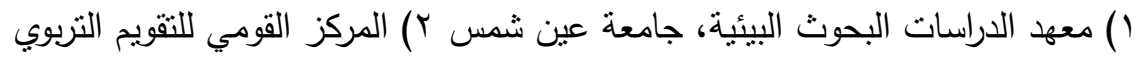

\section{المستخليه}

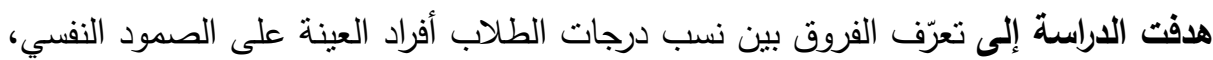

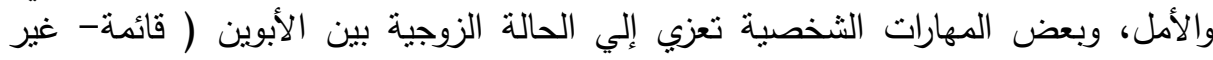

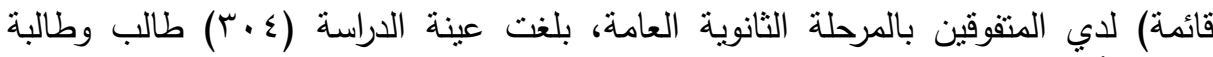

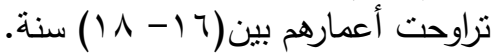

منهج الدراسة: انتهجت الدراسة الحالية الدانة خلادل مراحل إعدادها وتتفيذها المنهج (الوصفي التحليلي) الملائم لموضوع وأهداف الدراسة. فروض الاراسة:

1- توجد فروق دالة إحصائية في أبعاد الصمود النفسي (الكفاءة الثخصية- الكفاءة الأسرية-

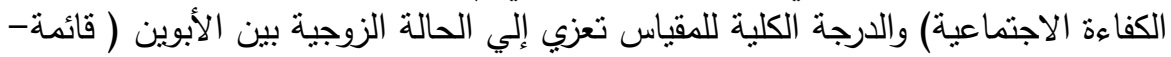

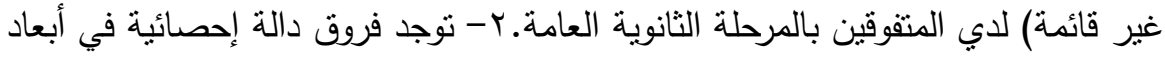

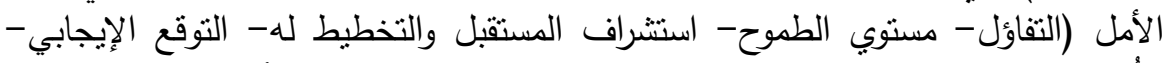

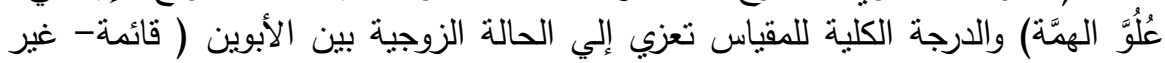

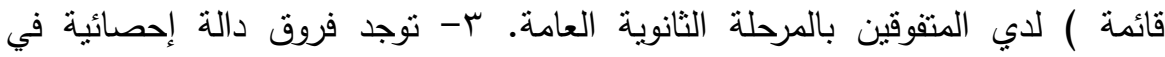

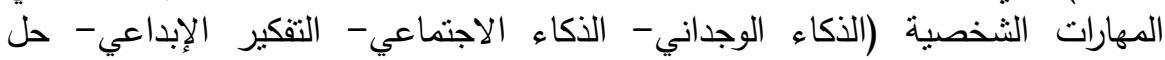

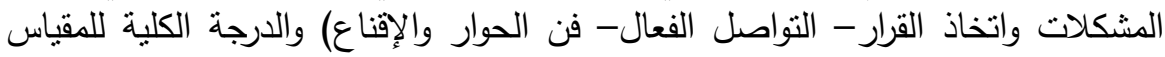

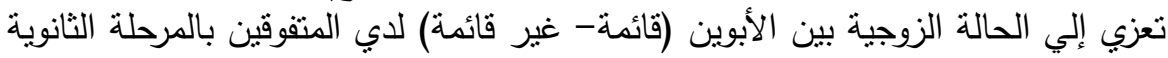

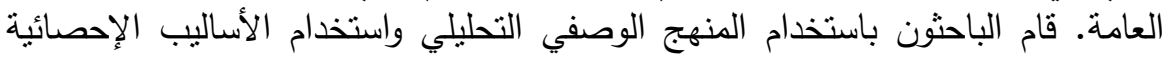

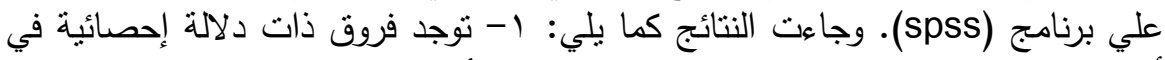

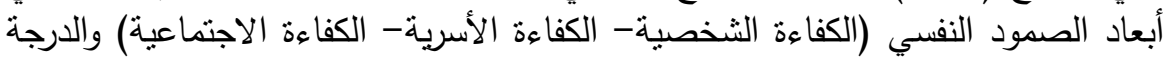

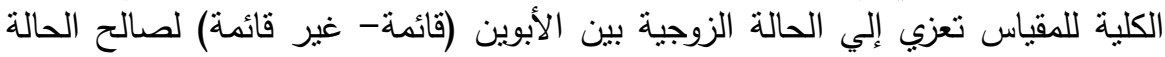

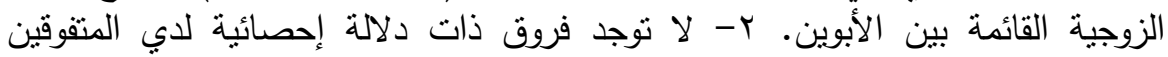

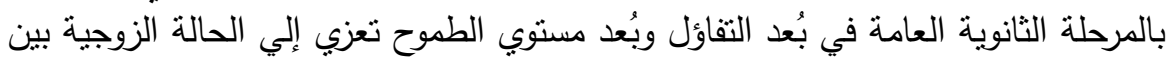

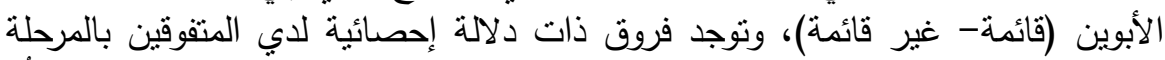

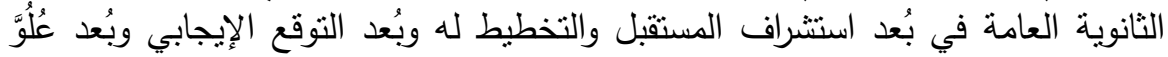

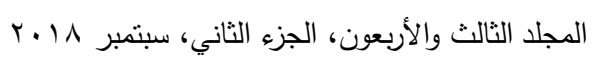


الهمَّة والدرجة الكلية لمقياس الأمل تعزي إلي الحالة الزوجية بين الأبوين (قائمة- غير

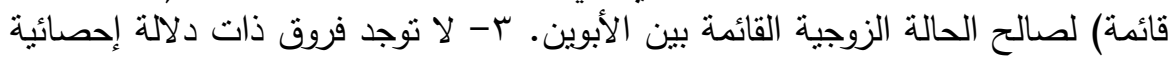

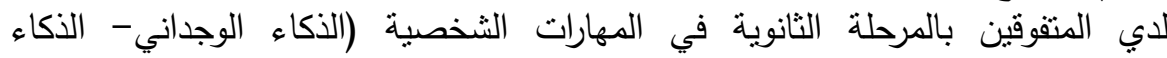

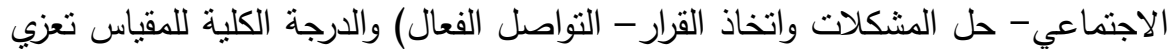

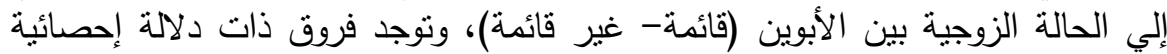

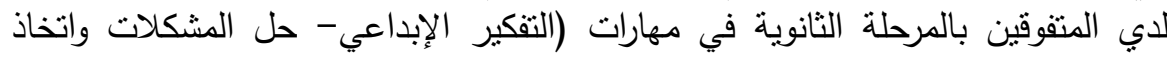

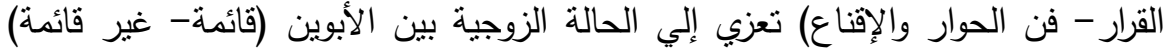

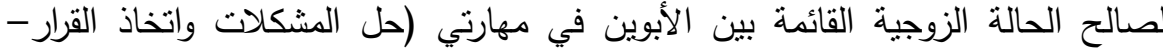

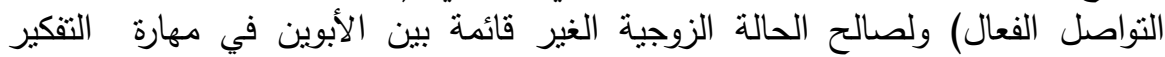

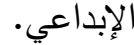

كلمات دالة: الصمود النفسي، الأمل، المهارات الثخصية، المتفوقين بالمرحلة الثانوية العامة.

\section{0}

الثباب يشكل أهم قوة بشرية لأب مجتمع، فهم مصدر الطاقة والتجديد والتغيير والإنتاج. والعلاقة التي تربط الإنسان بالمجتمع علاقة تبادلية، وليست علاقة سلبية أو متضادة، فيتفاعل فئل الفرد مع المجتمع، ويتكون التماسك والتثابك بأثنكاله النقافية، والاقتصادية، والنفسية، وبتأثنير هذا التبادل والتفاعل يحصل التكامل النفسي للفرد ( صالح سليمان، ... . ). وعندما نبحث في المهارات الثخصية للمتفوقين فهذا يعني الإجابة علي مجموعة من التساؤلات المتصلة بالسلوك الخاص بهم، وعن قدرتهم علي التواصل الفعال، ومواجهته المشاكل، والأزمات، واتخاذ القرارات، وفاعلية الذات لايهم وغيرها. فقد يواجه الطلاب المقبلون على سن البلوغ في القرن الحادي والعشرين مهام وتحديات لا يمكن أن يتصورها آباؤهم بسبب توفر الأجهزة

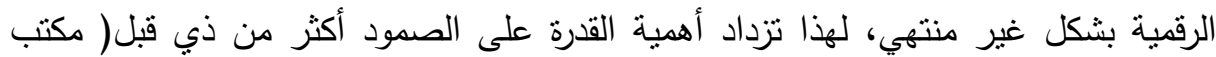

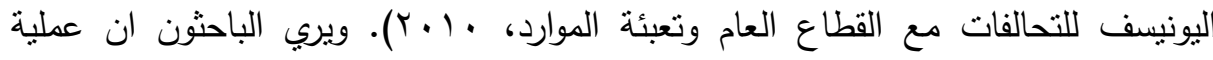

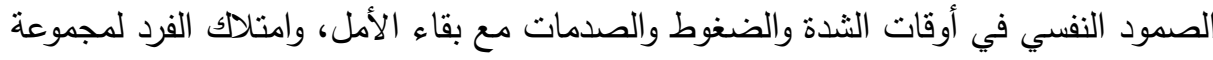
المهارات الثخصية لمواجهة مصادر الضغوط التي يمكن أن تحميه من التعرض لآثارها النفسية. 


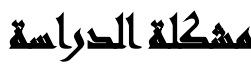

تتفق الدراسات والنظريات السيكولوجية على أن مرحلة الثباب من أهم المراحل التي

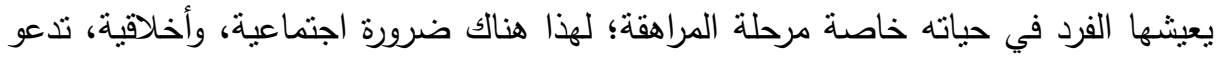

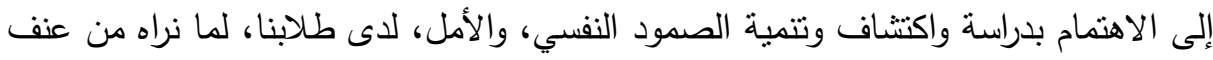
في العلاقات الاجتماعية بين طلبة المرحلة الثانوية، وتدني الدافعية الذاتية للطلبة، جراء

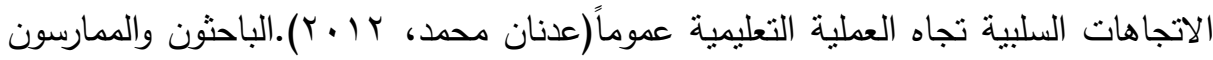
(Snyder, Ilardi, Michael, \&Cheavens, 2000; Snyder, في العلاج النفسئهن Michael, \& Cheavens, 1999; Snyder \& Taylor, 2000; Snyder, Irving, \& Anderson, 1991; Yalom, 1995) للعملاء حيث نظرت الدراسات في دور الأمل في تحسين العميل خلال المراحل المبكرة من الإندابه العلاج على سبيل المثال (Fennell\& Teasdale, 1987) وقد حققت نتائج عالية في علاقة الأمل العلاجية الإيجابية(Irving et al. 2004) وقد برز الكثير حول العوامل التي تسهم في الصمود النفسي في علم النفس التنموي والطب النفسي حيث كثفت دراسات رائدة والتي أجريت لفهمه والتوصل إلي نموذج يتضمن التفاعل المركب بين العوامل المهددة بالخطر والعوامل الواقية بهدف تطبيق هذه المعرفة في الممارسة التطبيقية منل دراسة ( Werner\& (Smith, 2001 ودراسة (Halkias, 2011) ودراسة (Arokiaraj et al. 2011) ودراسة كثفت عن عدد من العوامل الفردية، أو المهارات الثخصية، (Magnano et al. 2016) التي يعتقد أن تسهم في الصمود لدي الأطفال والمراهقين، من خلال تحديد الارتباطات النفسية

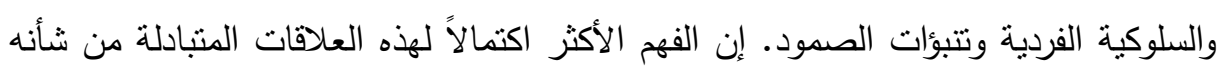
أن يؤدي إلى فهم أكبر للصمود (Tiet et al. 1998). وقد قدمت هذه الدراسات إسهامات في

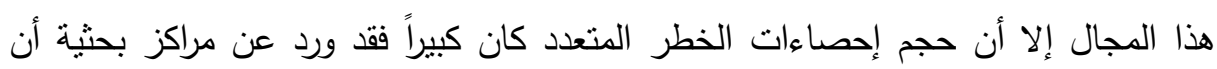

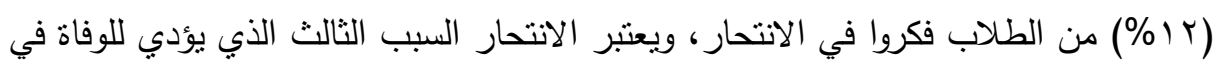

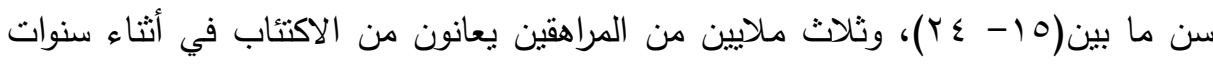

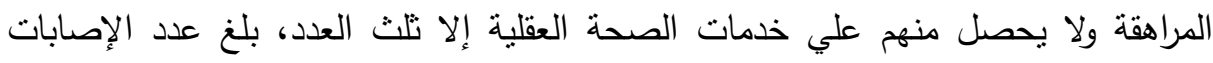

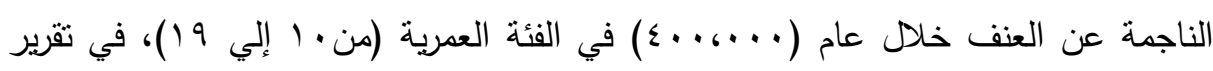

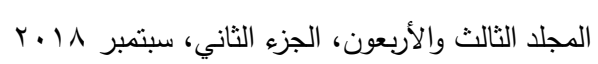


صادر عن هيئة قومية فإن طالباً من كل سبعة طلاب يتعرض للبلطجة في المدرسة ويوجد في كل فصل ثلاثة أو أربعة ضحايا للبلطجة وكثير من الضحايا ينعزل نتيجة للبلطجة (سام لبنه

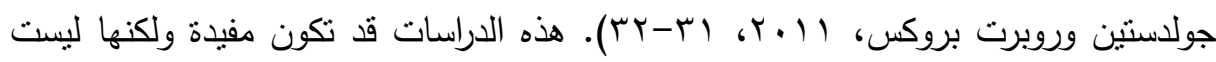

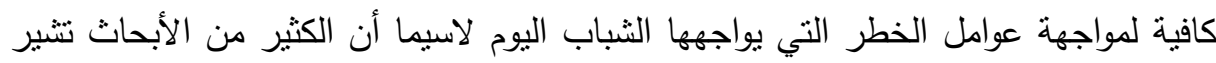

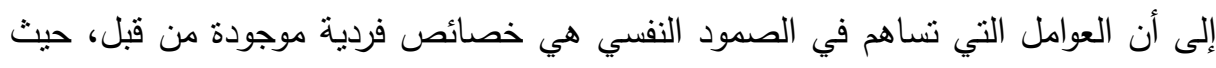

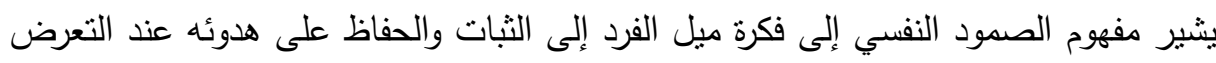

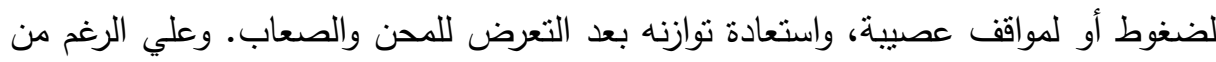

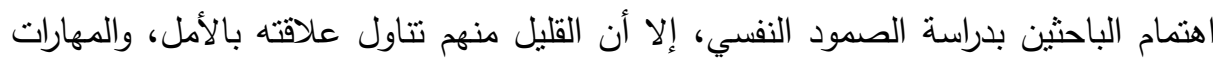
الثخصية، وتأثثر ذلك علي المتفوقين بالمرحلة الثانوية العامة. وهذا ما سعت إليه إليه الدراسة الحالية بهدف تحديد مدي القدرة علي الصمود النفسي، والأمل، والمهارات الثخصية، لديه وهائه المتقوقين بالمرحلة الثانوية العامة وتتطلب هذه المشكلة الإجابة علي

\section{أسئلا الترواسة}

1- ما مدي الفروق بين المتفققين بالمرحلة الثانوية العامة في الصمود النفسي للحالة الزوجية

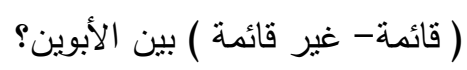

r- ما مدي الفروق بين المتفوقين بالمرحلة الثانوية العامة في الأمل للحالة الزوجية ( قائمة-

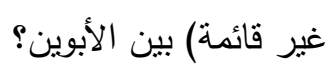

r- ما مدي الفروق بين المتفوقين بالمرحلة الثانوية العامة في المهارات الثخصية للحالة

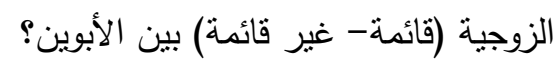

\section{أهمية القوراسة}

تستمد الدراسة الحالية أهميتها من:

1- تتاولها لموضوع الصمود النفسي، وعلاقته بالأمل، والمهارات الثخصية في ضوء الحالة الزوجية بين الأبوين للمتفوقين بالمرحلة الثانوية العامة.

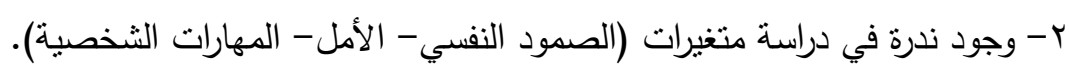

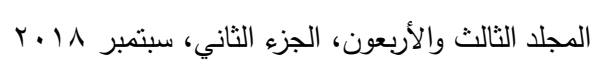


r- الدراسة تساعد المتفوقين بالمرحلة الثانوية العامة علي القدرة علي الصمود والأمل وتتمية المهارات الثخصية.

ع - تفيد هذه الدراسة الإخصائيين الاجتماعيين والمرشديين النفسيين والمؤسسات التربوية والنفسية والاجتماعية والتعليمية التي تُقدم خدمات تربوية ونفسية واجتماعية وتعليمية

للطلاب.

\section{أمساهي الدواسمد}

هدفت الاراسة الحالية إلي: 1-إلقاء مزيد من الضوء حول مفاهيم (الصمود النفسي- الأمل- المهارات الثخصية). r- التعرف علي الصمود النفسي لاي المتقوقين بالمرحلة الثانوية العامة. ب- التعرف علي الأمل لدي المتفوقين بالمرحلة الثانوية العامة. ع- التعرف علي المهارات الثخصية لدي المتفوقين بالمرحلة الثانوية العامة.

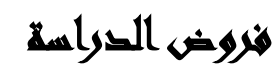

1- نوجد فروق دالة إحصائية في أبعاد الصمود النفسي ( الكفاءة الثخصية- الكفاءة

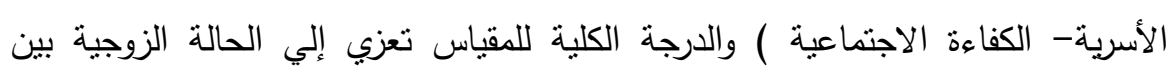
الأبوين ( قائمة- غير قائمة) لدي المتفوقين بالمرحلة الثانوية العامة.

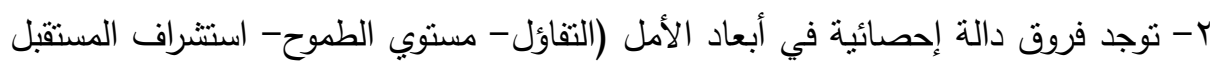

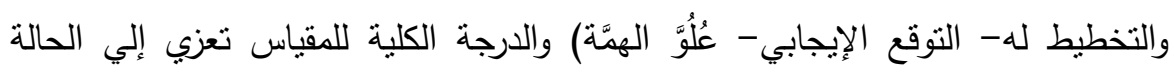
الزوجية بين الأبوين (قائمة- غير قائمة) لدي المتفوقين بالمرحلة الثانوية العامة.

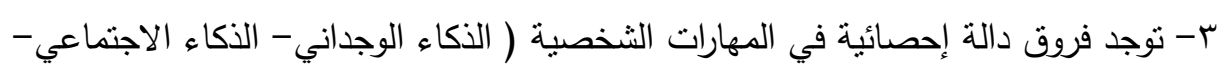
التفكير الإبداعي- حل المشكلات واتخاذ القرار - التواصل الفعال- فن الحوار والإقناع) والدرجة الكلية للمقياس تعزي إلي الحالة الزوجية بين الأبوين (قائمة- غير قائمة) لدي المتفوقين بالمرحلة الثانوية العامة. 


\section{همطلحايت القراسلة}

الصمود النفسي: أحد البناءات الكبرى في علم النفس الإيجابي، وهو من المتغيرات النفسية الإيجابية الدالة على مقاومة الضغوط والأزمات النفسية والاجتماعية والإحباطات المتتالية التي لهي

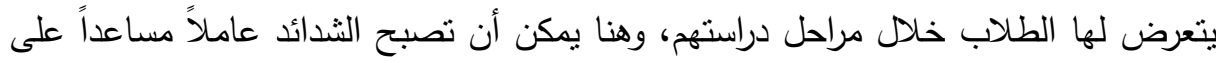
التحول الإيجابي والأمل في الحياة. فهو عملية تكيف ومجموعة من المهارات والقدرات

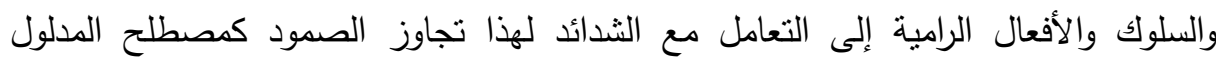

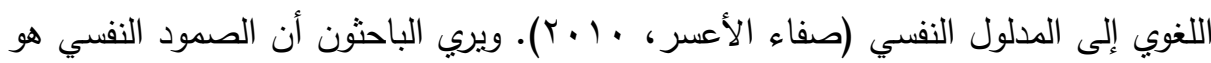
قدرة الفرد علي التعامل بكفاءة مع عوامل الخطر المختلفة من ضغوط وتوترات وتحديات

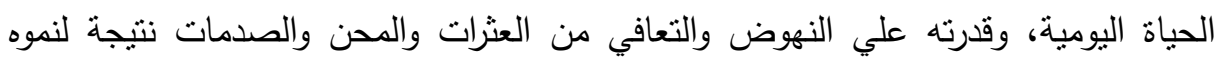
الإيجابي، وارتفاع عوامل الحماية والوقاية، التي نتكلت لديه من خلاد كفاءته الثخصية، وتتشئته الأسربة، والمساندة الاجتماعية. الأمل: ينظر سنايدر إلي الأمل علي أنه وجهة معرفية موجهة نحو تحقيق هدف ويعرفه بأنه: حالة دافعية موجبة تعتمد علي الثعور بالنجاح وطاقة موجهة نحو الهدف، وتخطيط لتحقيق هذا الهدف (Snyder, 2002). وهو إدراك الفرد أن رغباته وأهدافه يمكن تحقيقها، وذلك مونه

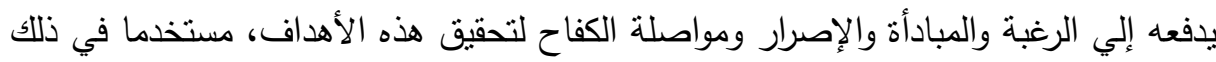

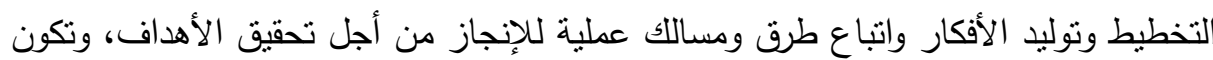

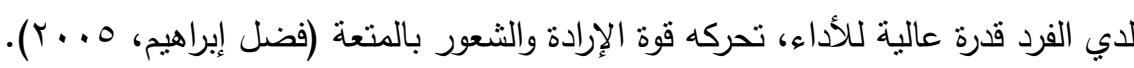
ويري الباحثون أن الأمل شعور وجداني متفائل يدفع الفرد إلي الطموح والاستشراف والتوقع باليه

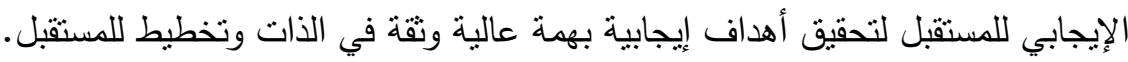
المهارات الشخصية: تسمى هذه المهارات في علم النفس بمهارات توكيد الذات وهدفها تعزيز الإحساس بقيمة الإنسان الذاتية، وهي مهمة للإنسان كي يحيا واثقاً بنفسه مؤكدًا لذاته

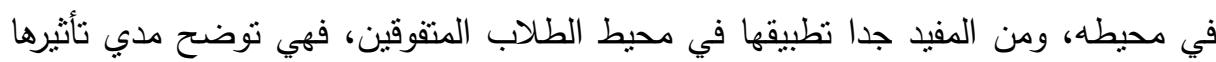

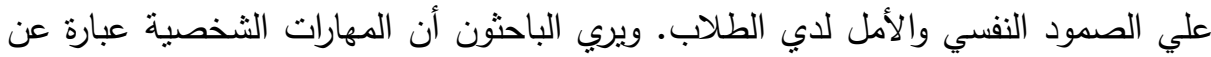


قوى كامنة في شخصية الفرد نعبّر عن نفسها بأشكالٍ مختلفة من السّّلوك الإنساني الرّاقي

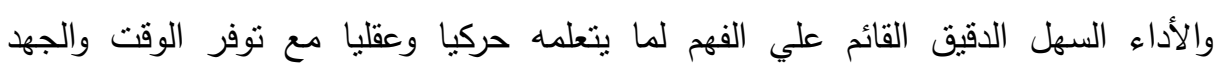

والتكاليف.

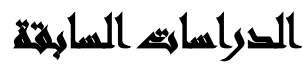

اطلع الباحثون على الدراسات التي شملت متغيرات الدراسة فلا توجد دراسات ربطت بين متغيرات الدراسة الحالية مجتمعة ولهذا حاولنا جمع الدراسات السابقة والتي على الأقل شملت متغيراً واحداً من متغيرات الدراسة وهي علي النحو التالي:

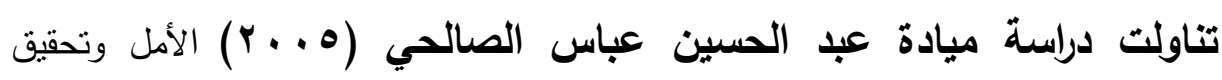

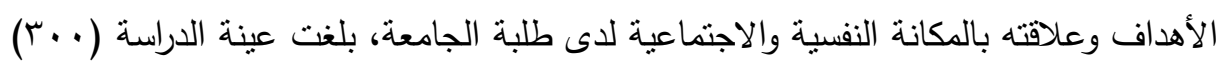
طالب وطالبة (10.1) طالب و (10.) طالبة. وخلصت الدراسة إلي التركيز على الاهتمام

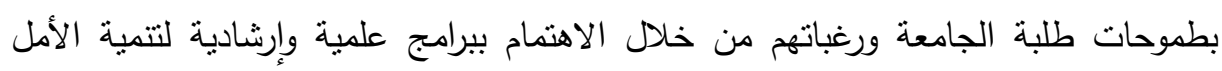

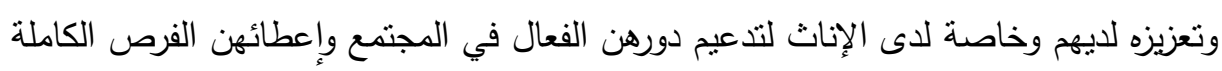
لتحقيق أهدافهن والتركيز على الأحداث الإيجابية ومتابعة نتمية قدراتهن وتعزيز طموحاتهن

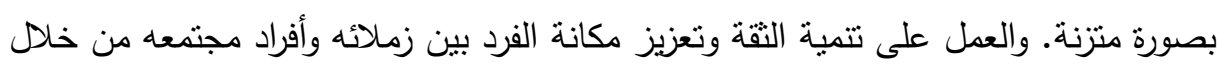

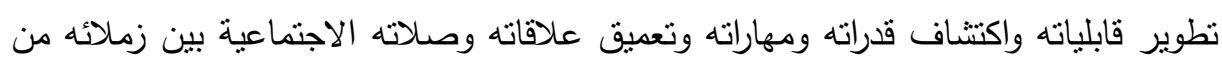

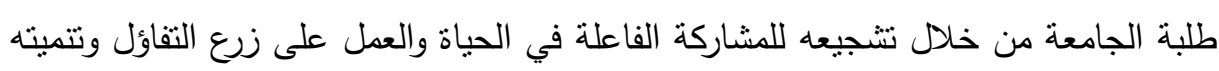
التحدي والمنافسة وتطوير الأهداف لأجل مواجهة معوقات الحياة. هدفت دراسة أمينة إبراهيم شلبي ( • ( • ب) إلي الكثف عن الفروق في الذكاء الوجداني

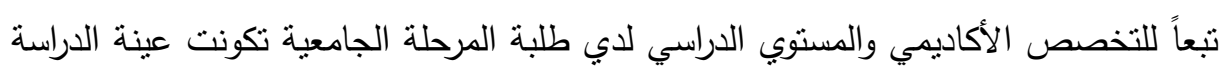

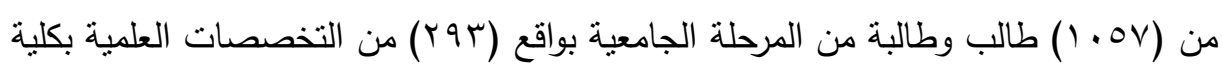

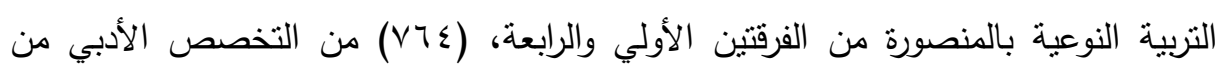

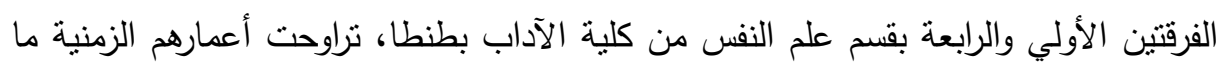

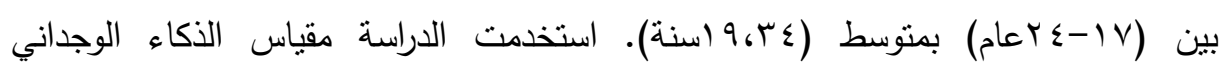
للراشدين إعداد الباحثة. أوضحت نتائج الدراسة وجود فروقاً ذات دلالة إحصائية بين طلبة لإنة

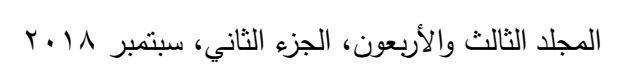


التخصص العلمي والتخصص الأدبي (علم النفس) في كل من الدرجة الكلية وبُعدي إدارة الضغوط والقابلية للتكيف علي مقياس الذكاء الوجداني لصالح التخصص العلمي وعدم دلالتها في بعدي الذكاء الثخصي و الذكاء الاجتماعي. هدفت دراسة أنسام شحادة الناطور ( • ( • ( ) إلي استقصاء فاعلية برنامج إرشادي في تحسين الدافعية للتعلم، والتحصيل الأكاديمي، ومهارات التعامل مع المشكلات المدرسية لدى المنسربين المراهقين العراقيين في الأردن، تكونت عينة الدراسة من ثناثين منسرباً من ونهابن Relief المراهقين العراقيين الذين ينلقون خدمات إنسانية في مؤسسة الإغاثة الدولية (RI) International لقياس متغيرات الدراسة الثلاثة، حيث تم قياس متغير الدافعية للتعلم من خلال الاستعانة

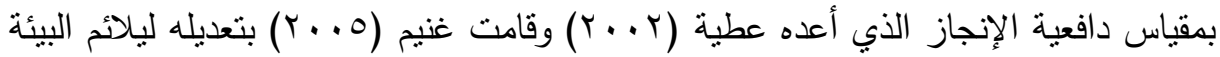
الأردنية. بينما تم قياس متغير التحصيل الأكاديمي من خلال استخدام ثلاثة امتحانات

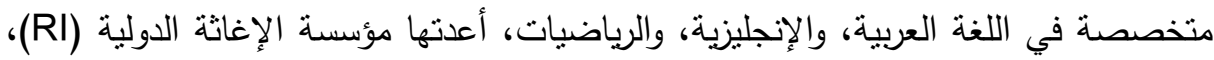

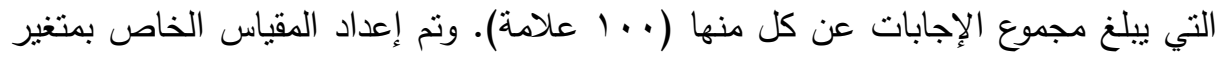

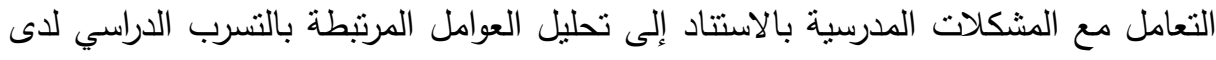
المراهقين العراقيين، والتي تم التوصل إليها من خلال مقابلات مركزة أجريت مع ذوي العلاقة

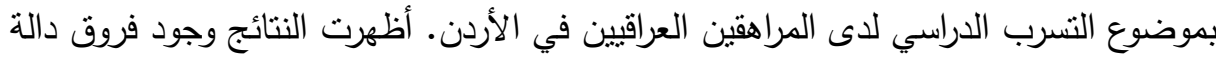

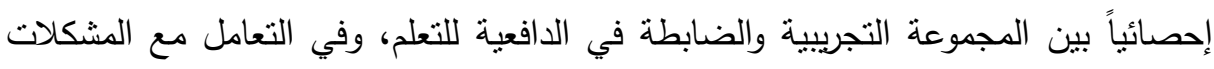

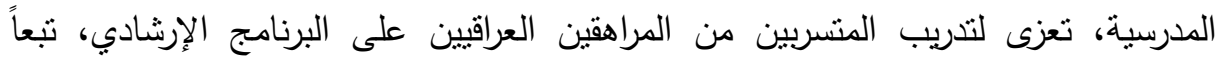
للقياسين البعدي والمنابعة. وعدم وجود فروق دالة إحصائياً بين المجموعة التجريبية والضابطة

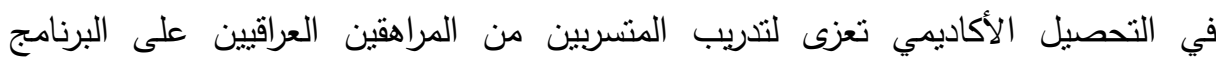
الإرشادي.

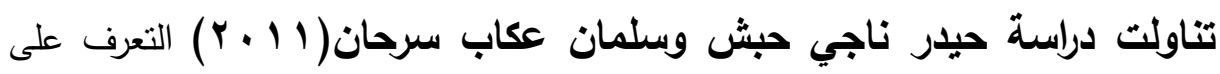
مستوى الأمل وتحقيق الأهداف والتعرف على مستوى السمات الثخصية لاى طالبات المرحلة الرابعة في قسم التربية الرياضية، تكونت عينة الدراسة من (•ء) طالبة، استخدمت الدراسة 
مقياس الأمل الذي وضعه (ليكرت) والذي أعده بالصورة العربية الكبيسي(9AvV) ومقياس

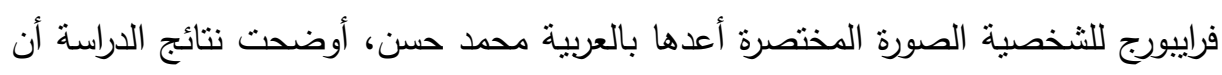

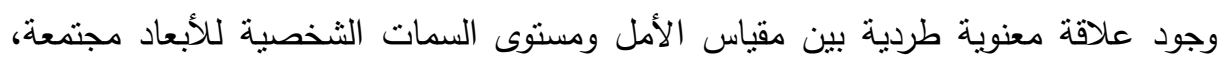

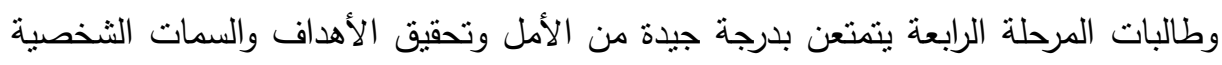
وأن السمات الثخصية انعكست بصورة إيجابية على مستوى الأمل و مستوى تحقيق الأهداف.

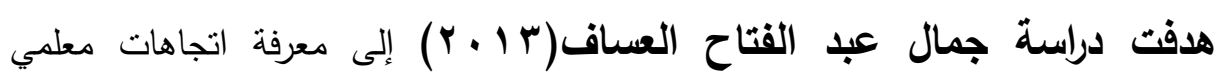
الدراسات الاجتماعية نحو تتمية مهارات التفكير الإبداعي لاى طلبة المرحلة الأساسية العليا في مديرية تربية عمان الثالثة، وعلاقته بمتغيرات: المؤهل العلمي والخبرة. تكونت العينة

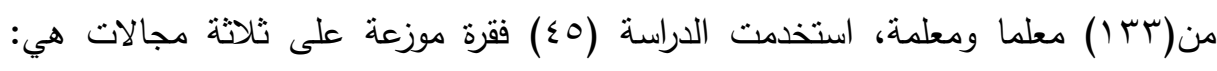
اتجاهات المعلمين نحو تتمية قدرات التفكير الإبداعي، والكثف عن المهارات الإبداعية

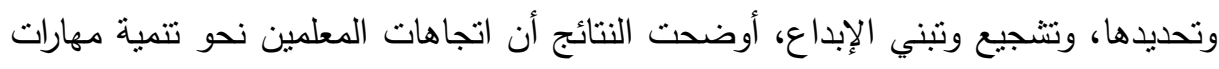

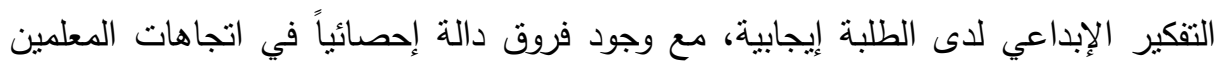

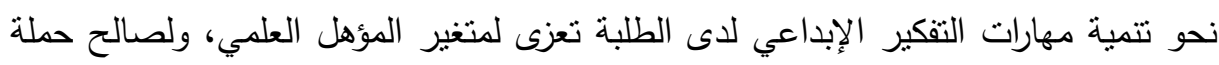

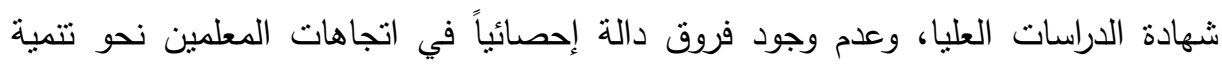
مهارات التفكير الإبداعي لدى الطلبة تعزى لمتغير الخبرة.

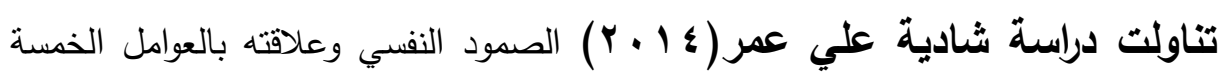
الكبرى للثخصية لاى عينة من الفتيات المتأخرات عن الزواج بمدينة الرياض، تكونت عينة

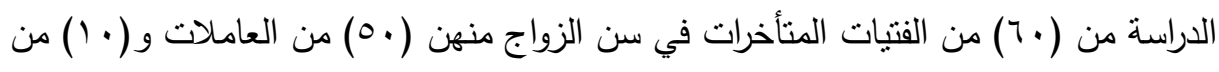

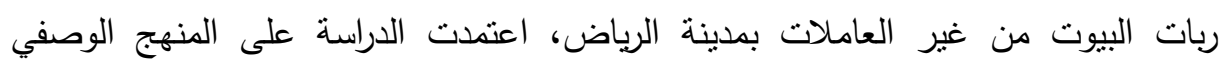

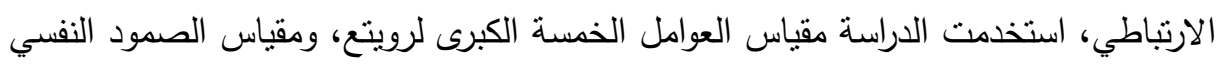
تعريب زينب درويش، أوضحت النتائج أن وجود ارتباط سالب لم يصل إلى درجة الدلالة

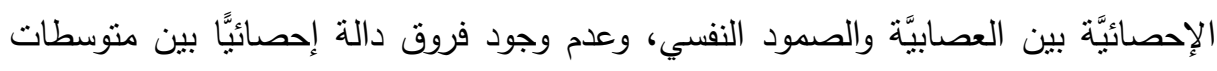

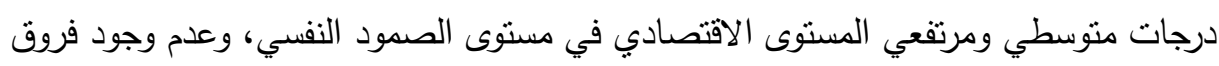

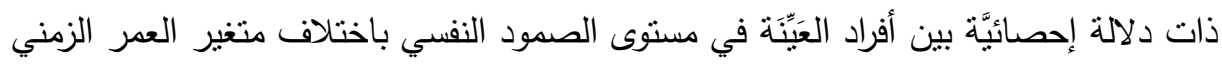
لادى المتأخرات في سن الزواج. 


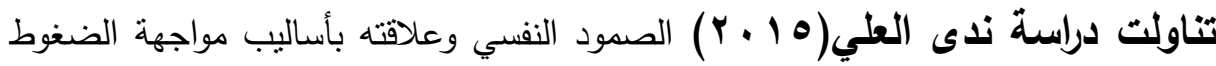

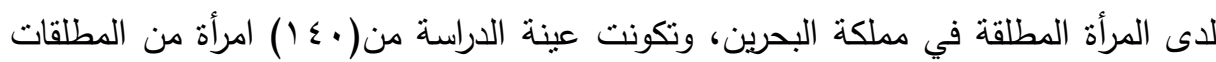

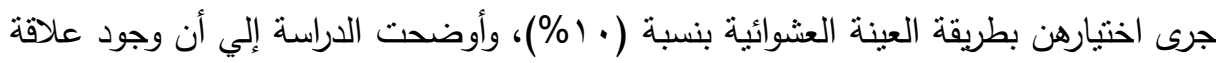

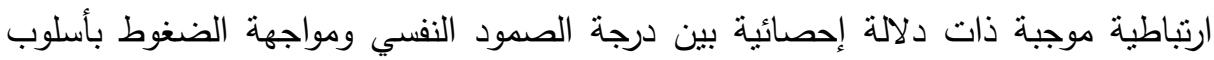
المواجهة العقلانية، فروقاً ذات دلالة إحصائية في درجة الصمود النفسي لدى المبه المرأة المطلقة

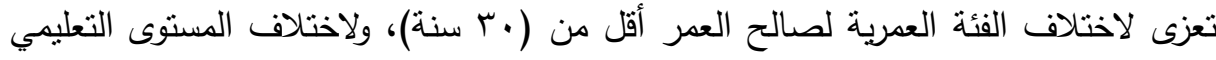
لصالح حملة المؤهل الجامعي، ولاختلاف الدخل الثهري لصالح الدخل الشهري (1 لـه دينار) فأكثر تعقيب علي الاراسات السابقة: أن معظم الدراسات السابقة ركزت على متغير واحد من متغيرات الدراسة الحالية، ولا نوجد دراسة واحدة علي حد علم الباحثين نتاولت متغيرات الدراسة

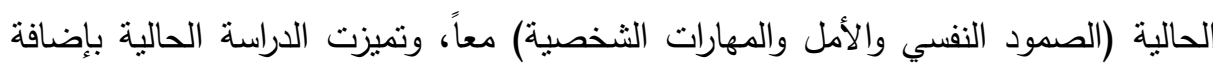

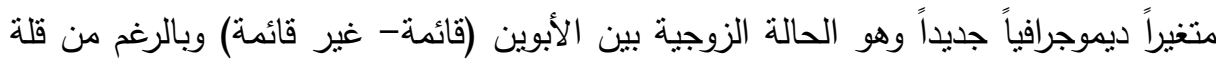

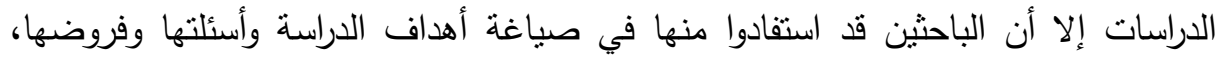
وكذلك الأساليب الإحصائية المستخدمة فيها، كما استفادوا منها في إعداد واستخدام أدوات إنات

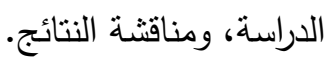

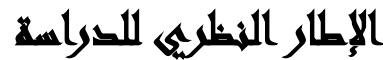

أولاً: الصمود النفسي: يعتبر الصمود النفسي بناء وافد من علم المواد التي تشتعيد خواصها بعد التعرض للطرق أو التمدد أو الانكماش، وهو نفس المعنى الذي بحمله الصمود

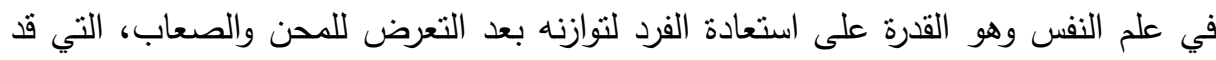
توظف لتحقيق النمو والتكامل، لهذا هو مفهوم دينامي دياليكتيكي يحمل في معناه الثبات

والحركة) (Horner\& Rew, 2003). 
نشأة وتطور الصمود النفسي: قالت ماجينيز أن البدايات الأولي في الكتابات عن الصمود

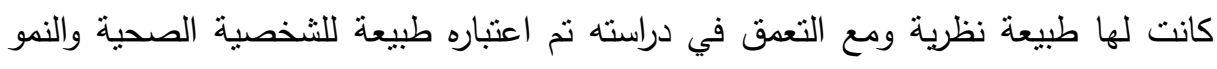

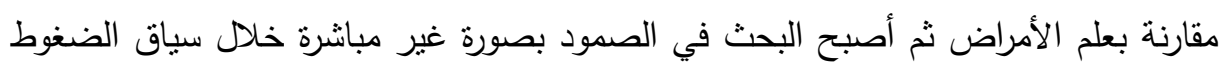

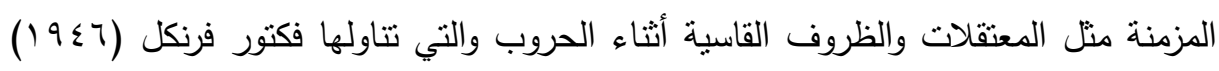
وبعد ذلك جاءت الدراسات المنبتقة من تحديد الفروق في الاستجابة للضغوط لدي الحيوانات

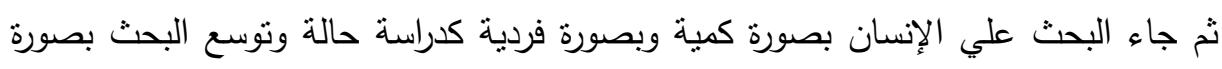

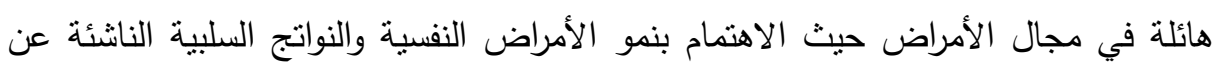
النمو في ظروف غير مواتية(6-Maginness,2007,3). حيث ظهرت دراسات الصمود النفسي في أواخر القرن الماضي، ولكنها نشطت في الفترة الأخيرة حيث زاد عدد البهاد الباحثين،

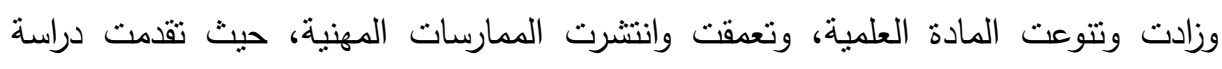

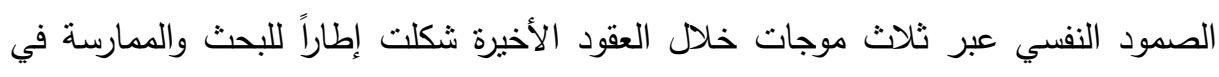

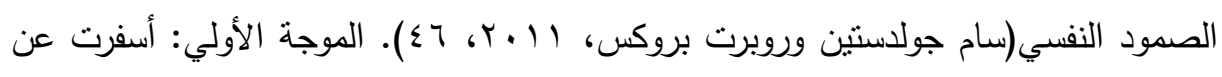
وصف جيد لظاهرة الصمود النفسي وتقديم مفاهيم أساسية ومناهج بحثية تركز علي الفرد. الموجة الثانية: تجيب عن النساؤل: كيف تعمل المتغيرات والعوامل الداخلية والخارجية، السلبية والإيجابية بما يؤدي إلى استعادة التوازن وتحقيق التوافق، أو إلى الانكسار وفقدان التوازني. الموجة الثالثة: ركزت على نوظيف نواتج الموجتين السابقتين في تتمية الصمود(صفاء

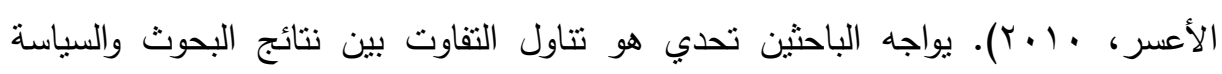

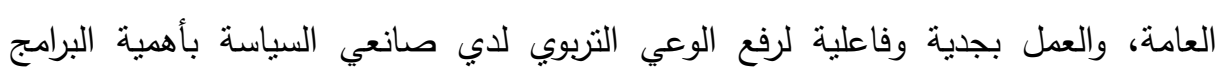

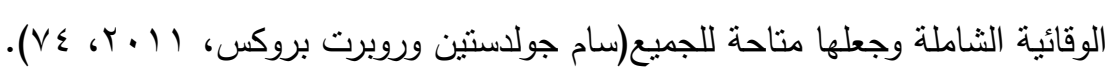
الخصائص التي يتمتع بها الأفراد ذوي الصمود النفسي: حددت الجمعية الأمريكية للطب ولنب

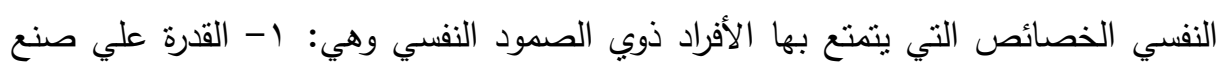

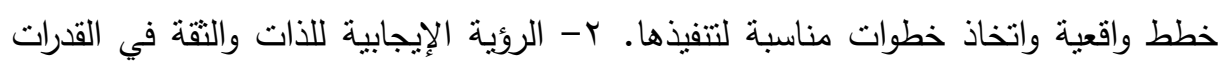

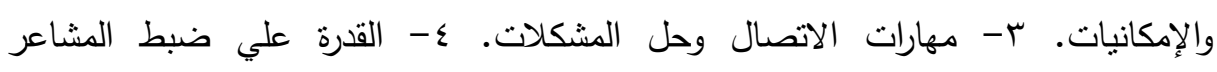

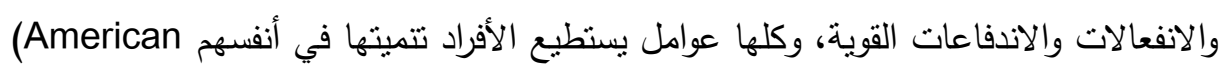
Psychological Association, 2000, p2)

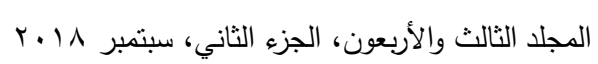


يتميز بها الأفراد ذوي الصمود النفسي نجملها في التالي: 1- الصبر (عثمان نجاتي،

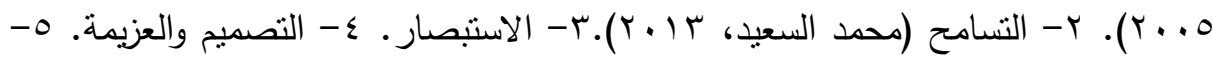
القيم الأخلاقية: :(Gayles, 2005, 251).

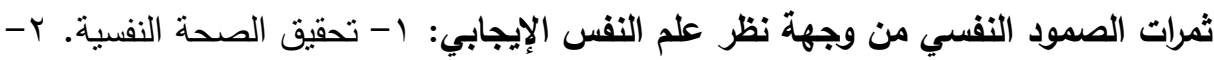

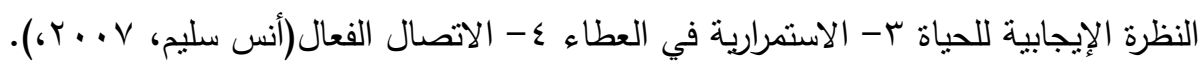

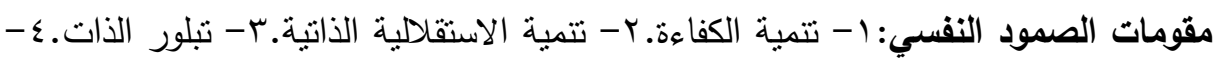

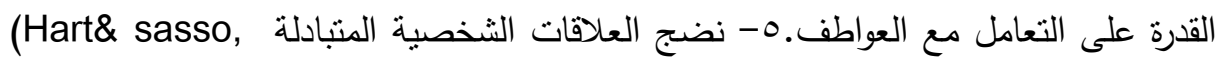
.2011,89) أبعاد الصمود النفسي:ا. بُعد الكفاءة الثخصية.r. بُعد الكفاءة الأسرية.r. بُعد الكفاءة الاجتماعية. ثُانياً: الأمل: يعد الأمل من المفاهيم المهمة في علم النفس، حيث تقع بحوث الأمل في قلب علم النفس الإيجابي، وقد بدأ تقديم المفاهيم المرتبطة بالأمل في الدراسات النفسية والطبية النفسية في خمسينات القرن العشرين(عسلية جودة، • ( • ب). ومفهوم الأمل من الناحية النفسية مختلف عن الاستعمال الثنائع والذي يري العديد من الناس أنه عبارة عن "ظاهرة الانفعال

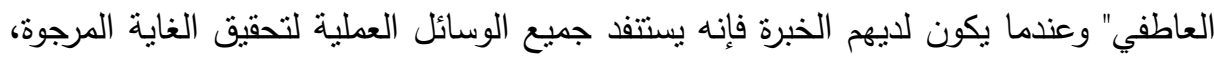

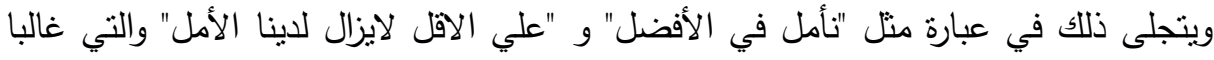
ما تلفظ وخاصة عندما يكون المرء عاجزا عن تحقيق الأهداف المهمة من خلال الجهود

الذانية التي يقوم بها (Peterson\& Byron,2008). نشأة وتطور الأمل: بدأت الأبحاث حول الأمل مع كارل ميننجر (909 (1) وفيكتور فرانكل

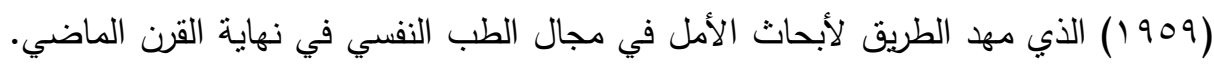
تحدي ميننجر المهنيين للنظر في مفهوم الأمل كمكون أساسي للممارسة السريرية. من ناحية أخرى، اعتمد فيكتور فرانكل على الرؤى الثخصية المكتسبة خلال سجنه في معسكرات الاعتقال لتطوير فكرة أن غياب الأمل يؤدي إلى اليأس وفقدان المعنى في الحياة. بعد ذلك بدأ

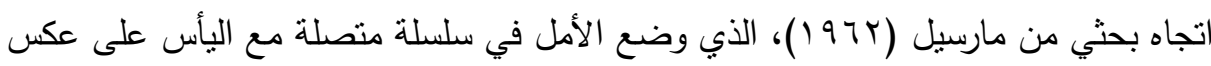


ذللك لينش (970 (1). وستوتلاند (979 (19) قاد الطريق لأبحاث الأمل في مجال علم النفس، مع

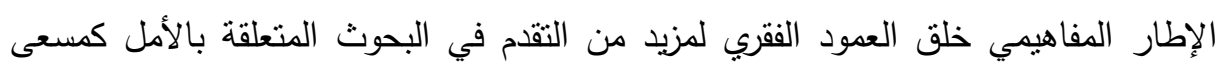

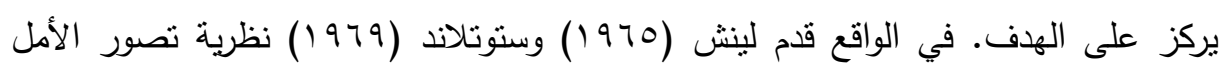
كتوقع لتحقيق الأهداف في المستقبل، مدفوعة بأهمية الهدف وتحفيز العمل داخل الفرد لتحقيق

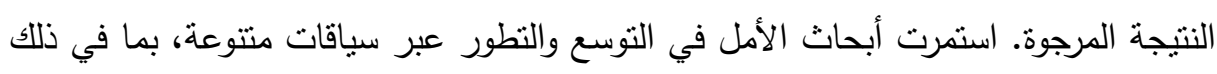

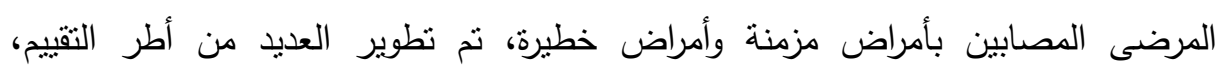
واستكثاف خبرات الأمل لاى المرضى، واستكثاف استراتيجيات تعزيز الأمل، وصف هيف هيندز (9191) الأمل كمفهوم عالمي وعامل جوهري، ضروري للحياة البشرية، على مدى السنوات التالية(Ashleigh Lauren Mutcher,2011). النماذج المفسرة للأمل: نموذج ستوتلاند(9 9 9) (1 ): صور ستوتلاند الأمل على أنه "توقع أكبر من الصفر" لتحقيق هدف من خلال عمله على النظرية النفسية الاجتماعية والمخططات

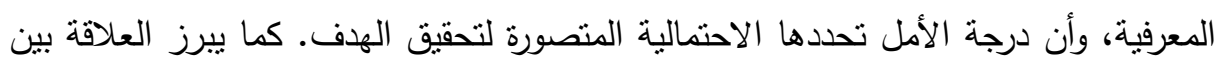

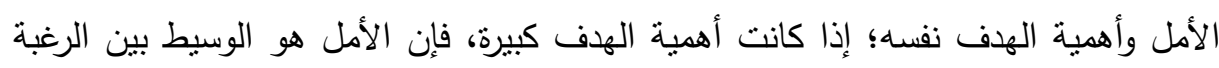

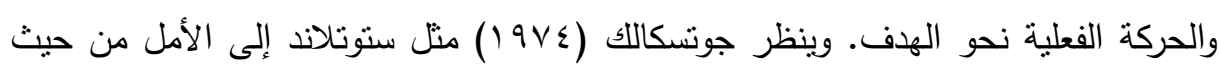

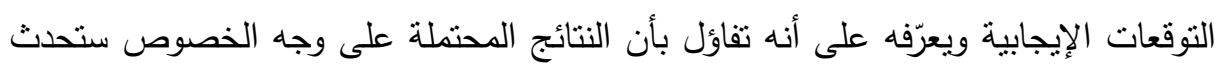

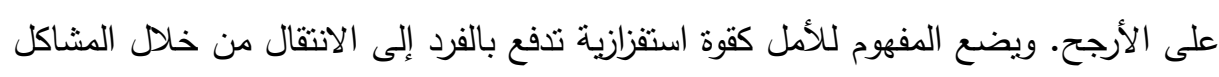

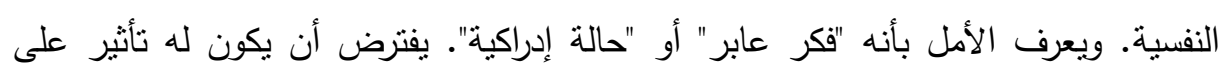
الفرد، يجب أن يكون قويا بما يكفي للحث على استجابة فسيولوجية موجهة نحو العمل.

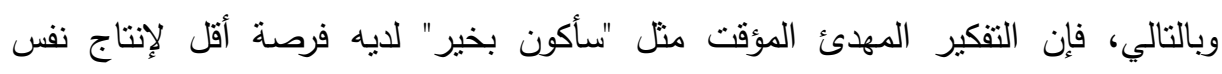
الاستجابة. ووفقا لهذا النموذج، فإن الفرد يقوِم ويتتاول النتائج المستقبلية باستخدام الموارد النفسية واستراتيجيات التكيف، منها الصمود النفسي. والفرد المفعم بالأمل يصل إليه عند تقييم الأهداف المستقبلية المرجوة على أنها واقعية وفي متتاوله (Boisvert,2001).

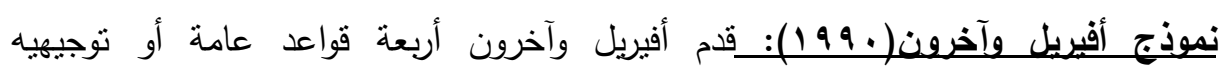
للأمل:(1) تشير القواعد الاحترازية إلى التأكيد على الواقعية والعقلانية. عندما يكون احتمال

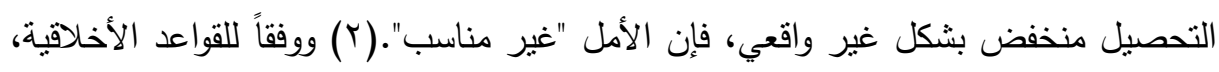

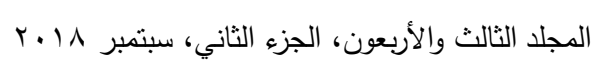


فإن موضوع الأمل محدد أيضاً بما هو مقبول شخصياً واجتماعياً؛ عندما تكون قابلية التحصيل منخفضة، فالأمل مرة أخرى غير مناسب.(r) تتطلب القواعد ذات الأولوية أن يكون

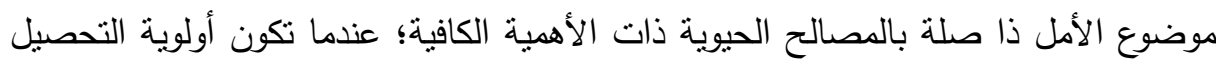

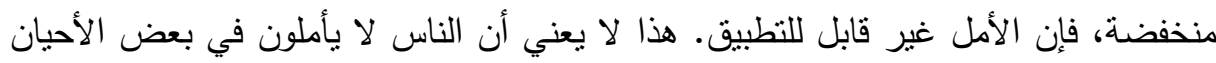

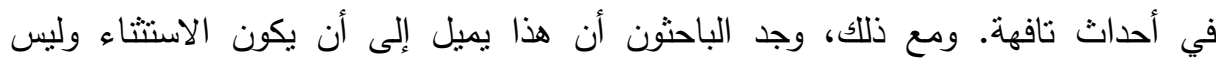

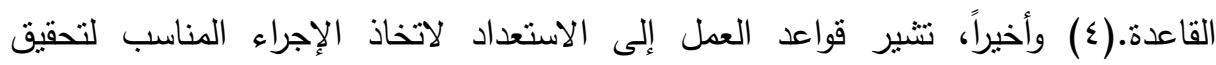

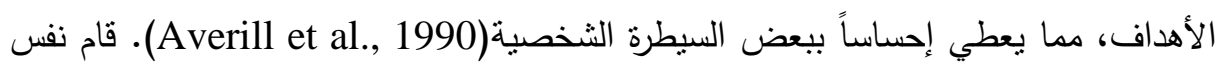
الباحثين بمقارنة الأمل بعواطف نموذجية(الغضب والحب) حدد المشاركون في هذه الدراسة

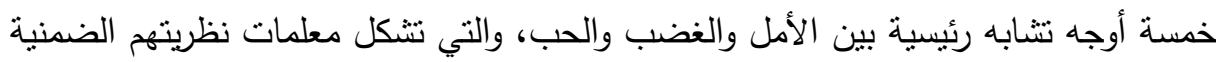
للأكل كعاطفة: أ) يصعب السيطرة على الجميع. ب) تؤثر على طريقة التفكير · ج) أنها تحفز السلوك. د) أنها تقود الناس إلى العمل بطرق غير معهودة. هـ) أنها تجارب عالمية. فإنهم

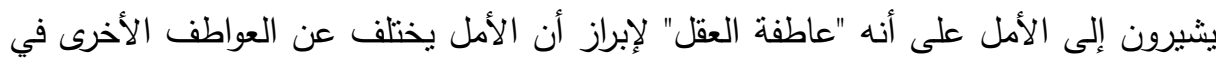

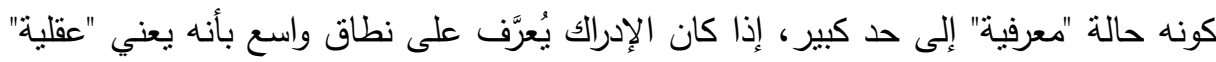

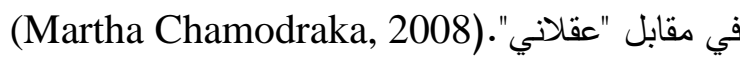

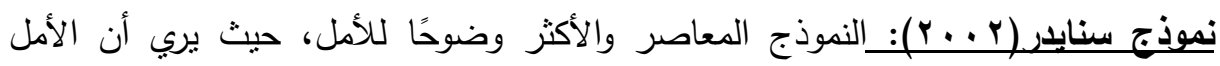
باعتباره إدراكًا يحتوي على التفكير الموجه نحو الهدف. يحدث عندما يدرك الناس أنهم قادرون

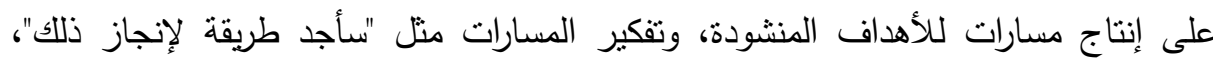

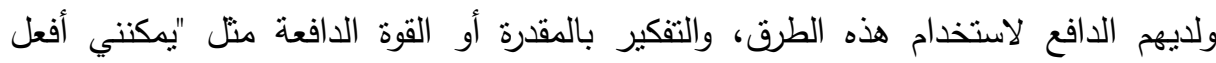
هذا"'."Martha Chamodraka, 2008). ولخص سنايدر نموذجه في أن للأمل بعدين هما: 1- السبل (التخطيط من أجل تحقيق الأهداف)، سبل التفكير هي وسيلة لربط الماضي لهين بالحاضر بالمستقبل من خلال الأهداف.ب- قوة الإرادة (الطاقة الموجهة نحو الهدف) الهدئ القدرة على البدء ومواصلة التحرك نحو الهدف على طول اختيار الطرق، ونحن نسمى هذا بالمقدرة على التفكير • تم تطوير ثناثة مقاييس الفروق الفردية التي تعكس بنية نموذج الأمل: مقياس 
الأمل كسمة، مقياس الأمل كحالة، مقياس الأمل للأطفال. في الآونة الأخيرة، تم وضع نظرية الأمل لتوضيح التغير الزمني لتسلسل الفكر الموجه نحو الهدف (Snyder, 2002).

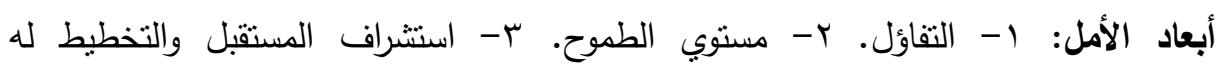

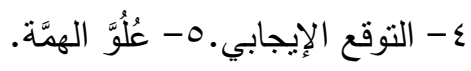

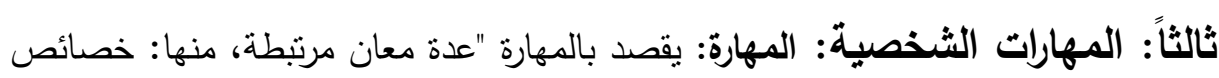

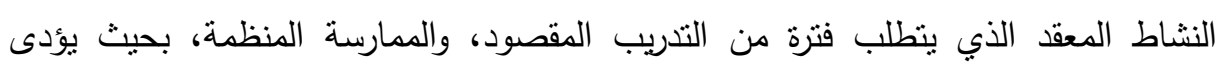

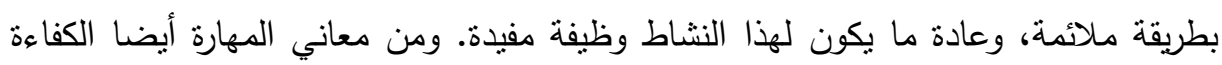

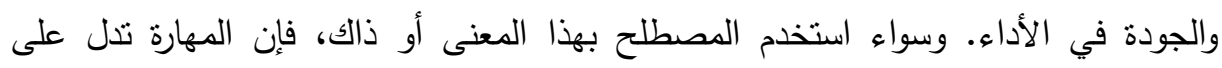

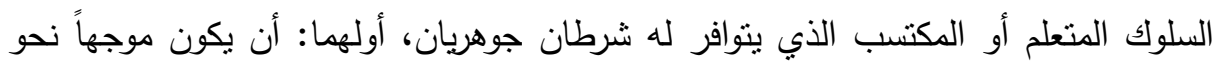

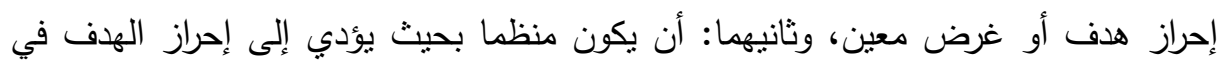

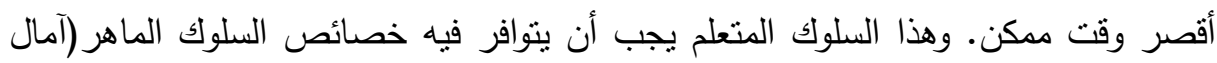
صادق، وفؤاد أبو حطب، ـ991). المهارات الشخصية: يري ميشيل أرجايل بأن المهارات

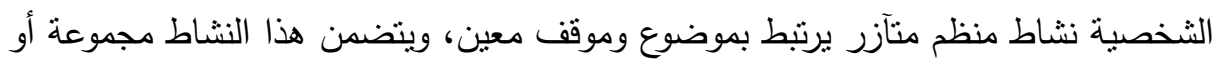

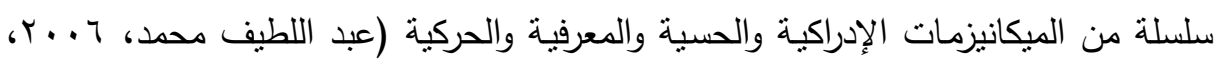

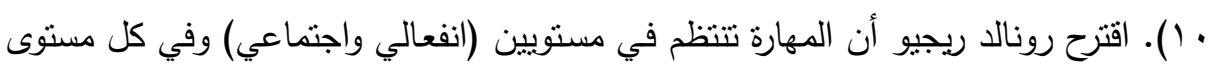
يتم الإفصاح عن المهارة في ثلاث مجالات:- التعبير : ويثير إلى القدرة على التعبير عن

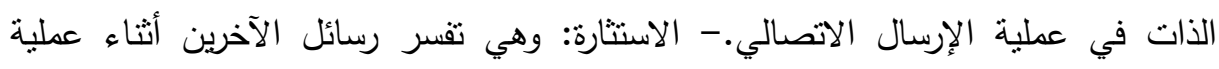

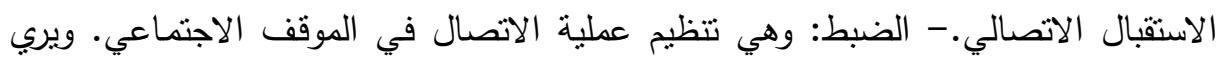

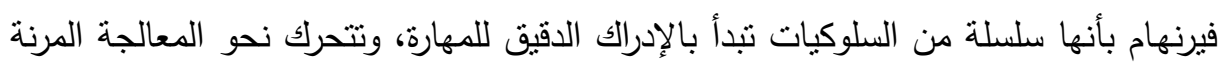

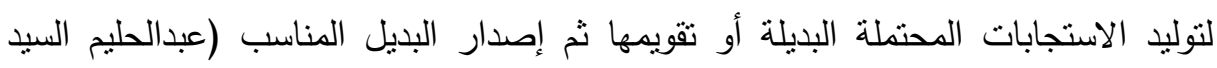

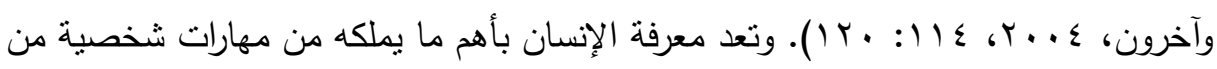

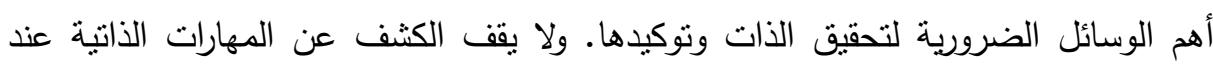

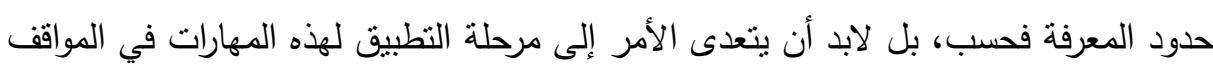

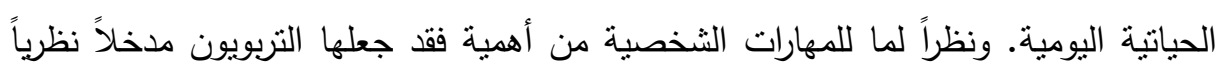

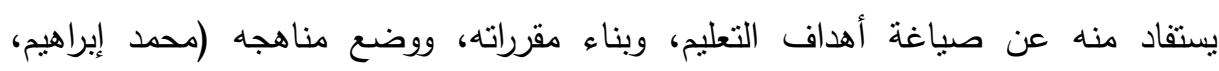

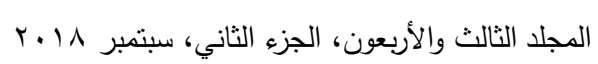




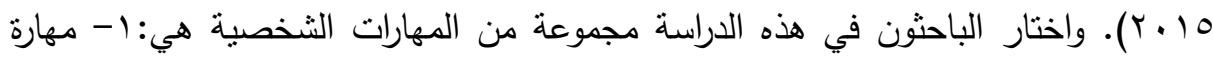

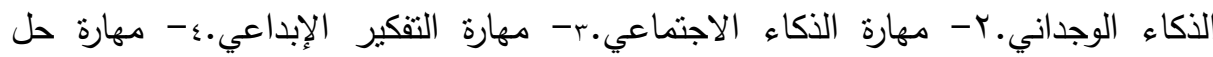
المشكلات واتخاذ القرار .ـ- مهارة التواصل الفعال. ـ - مهارة فن الحوار والإقناع.

\section{إجباءاهي القراسلة}

منهج الدراسة: انتهجت الدراسة الحالية خلد مراحل إعدادها وتتفيذها المنهج (الوصفي التحليلي). عينة الدراسة: استخدم الباحثون مجموعنين. المجموعة الأولى: تمثل العينة الاسنطلاعية وقوامها ( . . 1) طالب وطالبة، لغرض حساب الثبات والصدق لدقاييس الدراسة. المجموعة الثانية: العينة الأساسية وتستخدم لغرض اختبار الفروض وقوامها (ع • ب) طالب وطالبة. شروط اختيار العينة: أن تُختار العينة بشكل عشوائي من المتفوقين بالمرحلة الثانوية العامة- أن تشمل العينة البيئة الريفية والحضرية- أن تختار العينة من الصفوف الدراسية الثلاث في المرحلة الثانوية العامة- أن تختار العينة من الذكور والإناث. خصائص العينة: يوضحها الجدول التالي: جدول( (1): الخصائص الديموجرافية للعينة الأساسية

\begin{tabular}{|c|c|c|c|c|c|c|c|}
\hline المئويبة & التكرار & \multicolumn{2}{|c|}{ المتغير } & النسبة المئوية & التكرار | & \multicolumn{2}{|c|}{ المتغير } \\
\hline 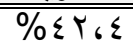 & $1 \% 9$ & ذكر & & \%भI, & 1117 & ريف & ئتة لעقلة ت \\
\hline $0 V_{6} 7$ & IVo & آنثي & لسوץ & $\% \Gamma \Lambda_{6} \wedge$ & 111 & حضر & بينه الإ \\
\hline$\% \leq 1,1$ & $1 \% 0$ & الأول(7 (سنة) & الصف & $\% \wedge \neg .0$ & TIT & قائمة & \\
\hline \%rr.q & $1 . r$ & الثاني (V V اسنة) & الدراسي & $\% 1 \pi_{6}$ & ¿1 & غيزي. & لين الأبوين \\
\hline \%ro & V7 & الثالث (1 (سنة) & والعمر & 101160 & & قائمة & \\
\hline
\end{tabular}

وتم تطبيق الدراسة الحالية على المتفقين بالمرحلة الثنانوية العامة تم اختيارهم بصورة عشوائية من البيئة الريفية بمحافظة الدقهلية (طلاب الددارس الثانوية العامة التابعة لإدارتي شرق وغرب المنصورة) والبيئة الحضرية بمحافظات القاهرة الكبرى (طلاب الددارس الثانوية العامة التابعة لإدارة الهرم وادارة بولاق الدكروري بمحافظة الجيزة وادارة شبرا الخيمة بمحافظة 
القليوبية). تراوحت أعمارهم (من 7 (اسنة إلي 1 ا سنة). وتم التطبيق علي أفراد العبنة

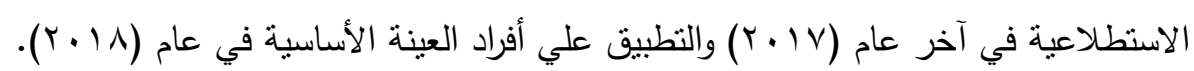
أدوات الدراسة: قام الباحثون بالاطلاع علي عدد من مقاييس (الصمود النفسي والأمل والمهارات الثخصية) والتي تم استخدامها في الدراسات السابقة، ثم قاموا بإعداد واستخدام

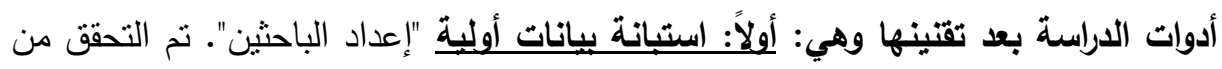
صدق الاستبانة عن طريق عرضها علي مجموعة من السادة المحكمين من أعضاء هيئة

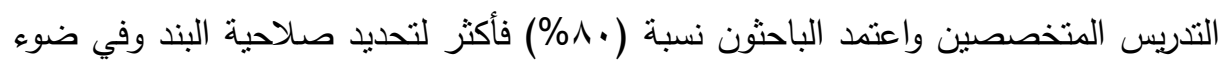

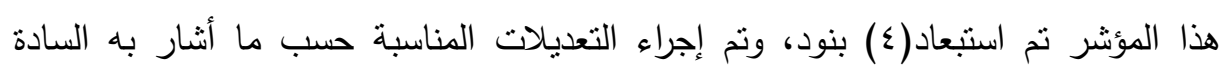

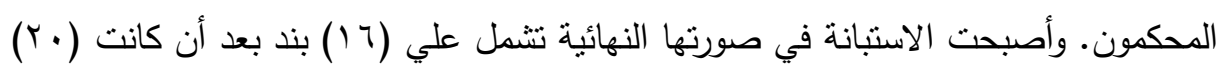

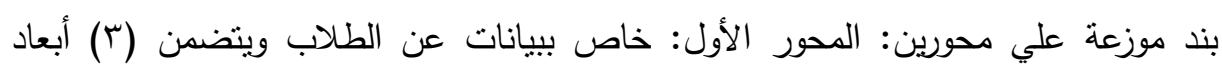
موزع عليها (^) بنود والمحور الثاني: خاص بييانات عن أسرة الطلاب ويتضمن (r) أبعاد موزع عليها (^) بنود. ثانباً: مقياس الصمود النفسي: "إعداد الباحثين" حيث قاموا بتقنين المقياس كالتالي: صلق المقياس: ا-صدق المحكمين: نم التحقق من صدق المقياس عن طريق عرضه علي إسئ

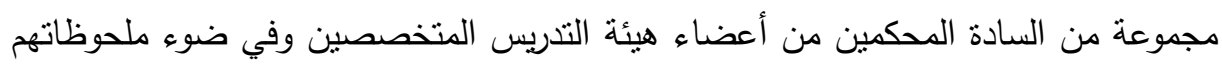

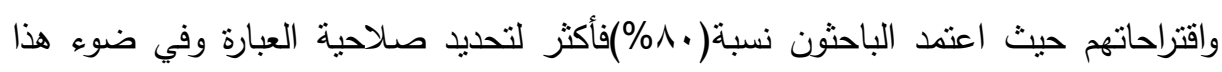

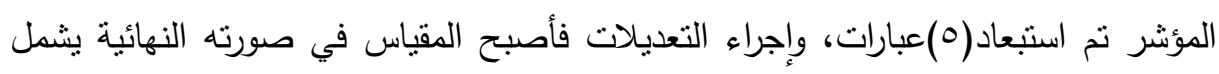

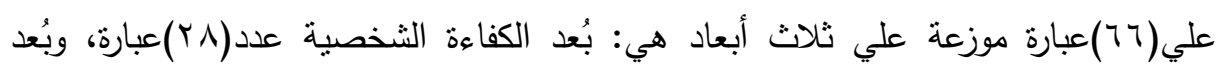

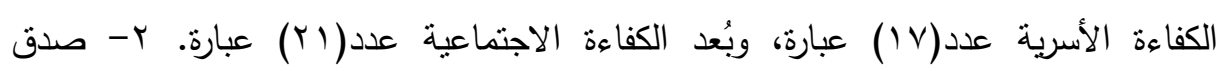

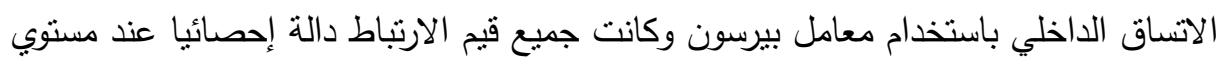

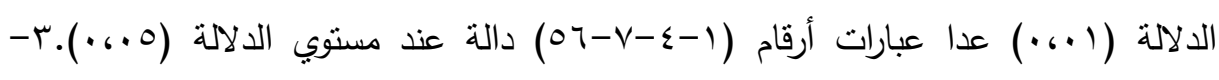

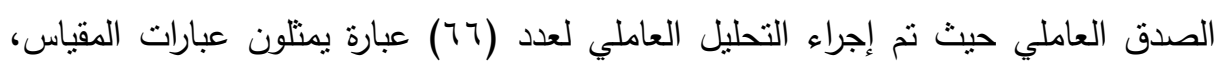

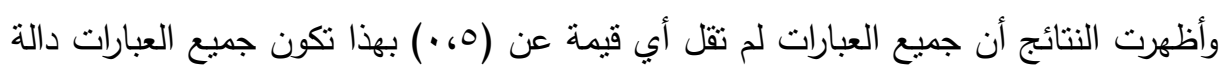

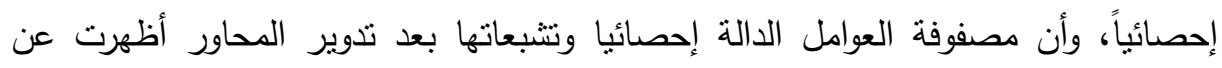

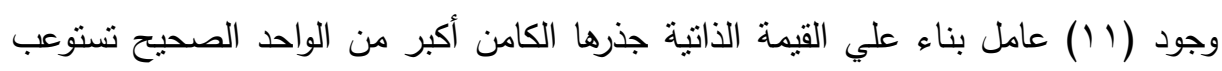

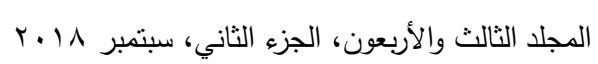




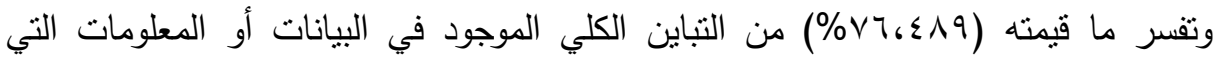

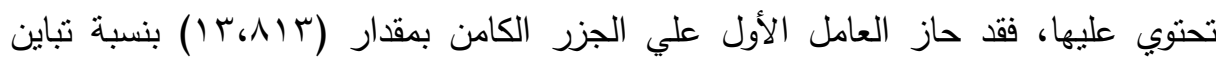

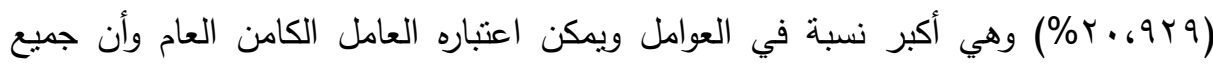

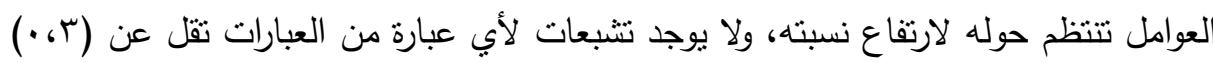

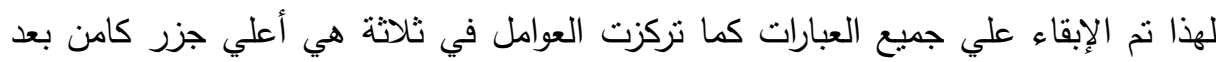

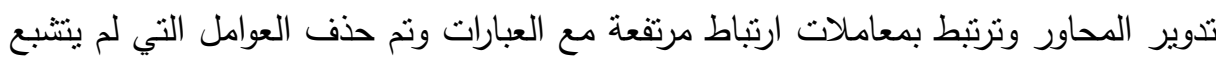

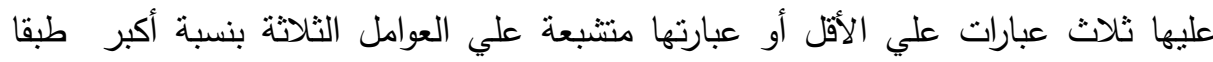

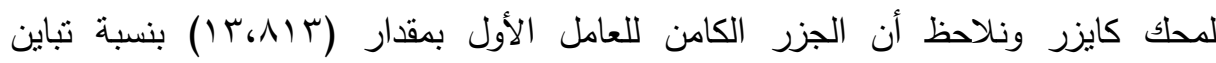

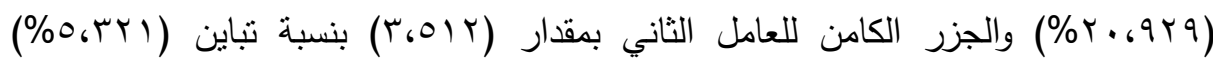

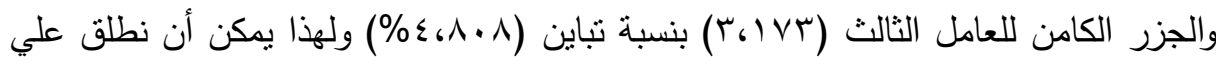

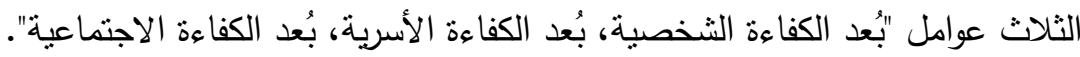

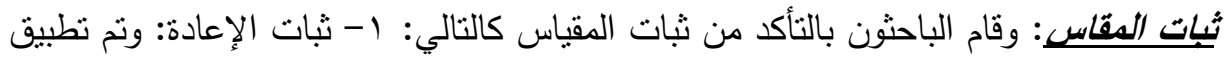

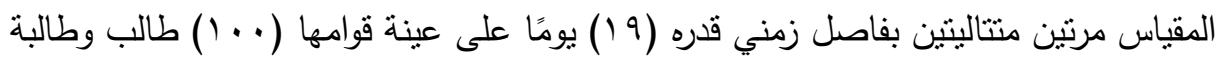

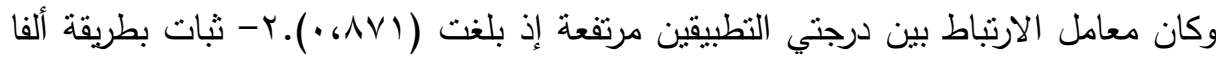

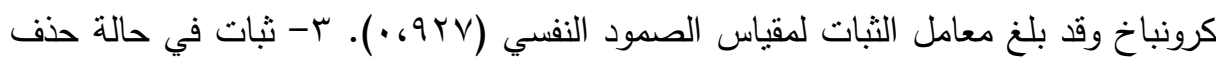

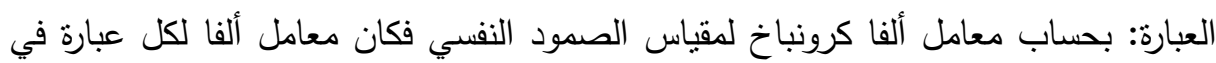

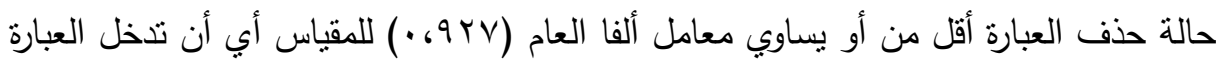

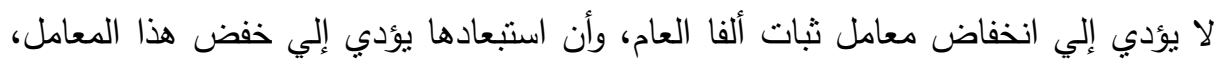

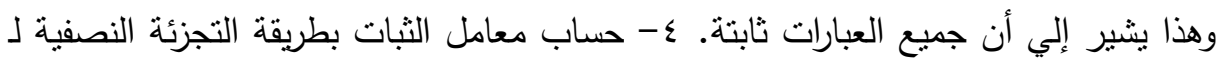

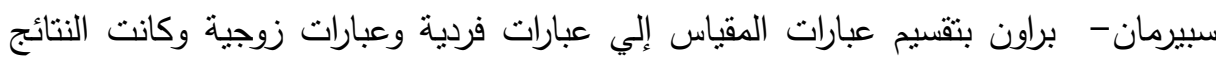

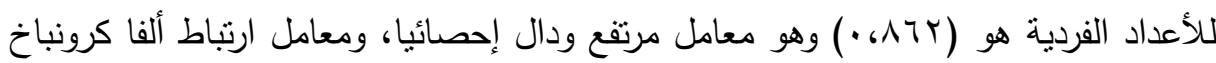

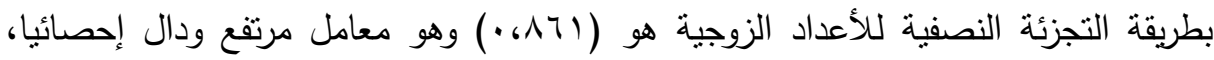

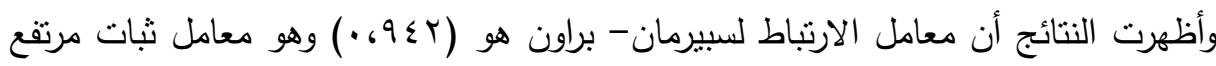


ودال إحصائيا وأكبر بقليل من معامل ألفا لجميع عبارات المقياس الذي يبلغ مقداره (9rv، • .) وهذا يدل علي ثبات المقياس.

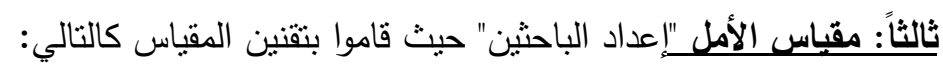

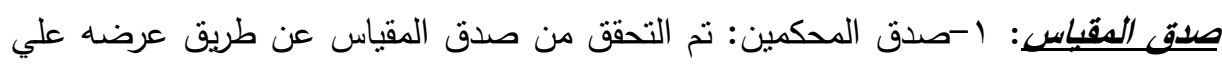

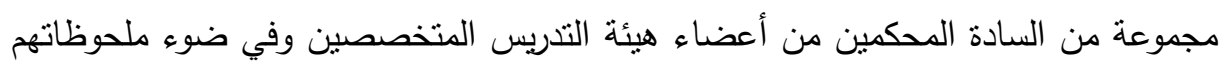

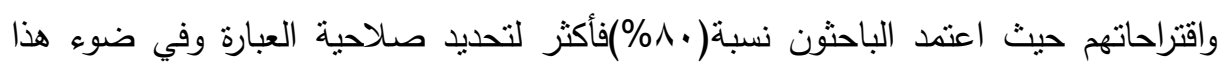

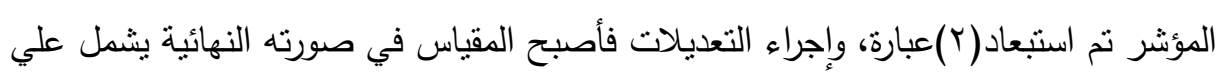
(VT) عبارة موزعة علي خمس أبعاد هي: بعد التفاؤل عدد (10) (1) عبارة، وبعد مستوي الطموح

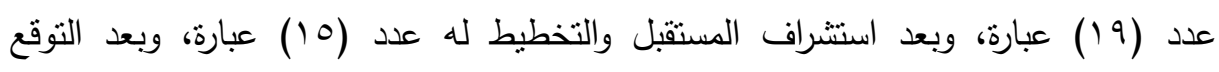

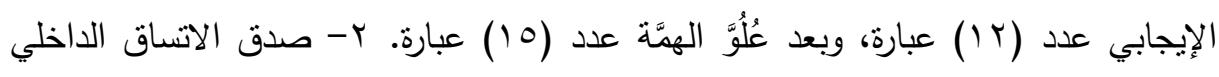

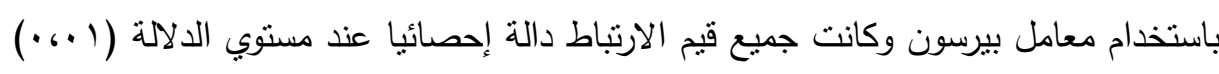

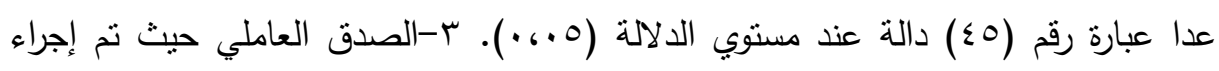

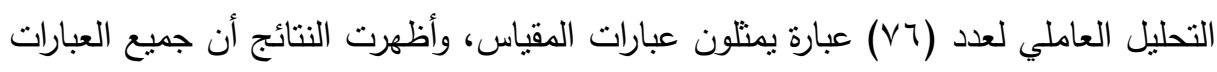

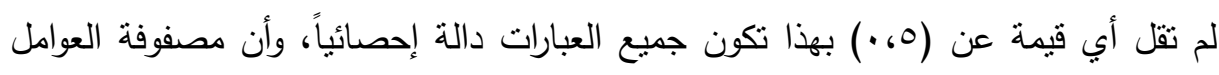

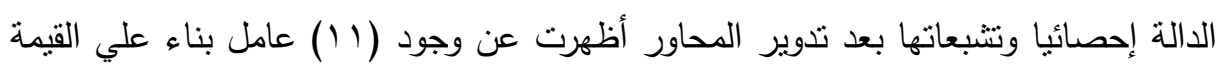
الذاتية جذرها الكامن أكبر من الواحد الصحيح تسنوعب وتفسر ما قيمته ( التباين الكلي الموجود في البيانات أو المعلومات التي تحتوي عليها ونلاحظ أن نسبة التفسير

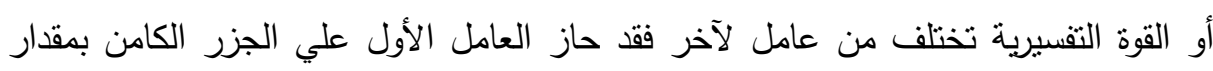

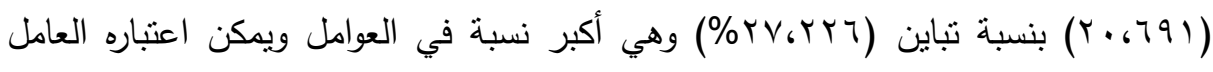

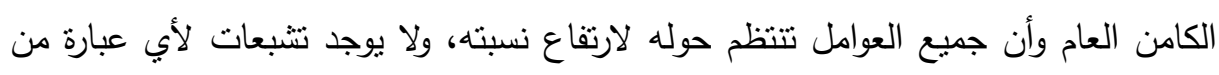

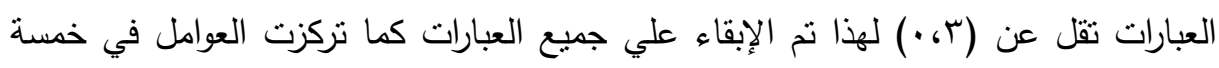
هي أعلي جزر كامن بعد تدوير المحاور وترتبط بمعاملات ارتباط مرتفعة مع العبارات وتم الإباء حذف العوامل التي لم يتشبع عليها ثلاث عبارات علي الأقل أو عبارتها منتبعة علي العوامل الخمسة بنسبة أكبر طبقا لمحك كايزر ونلاحظ أن الجزر الكامن للعامل الأول بمقدار

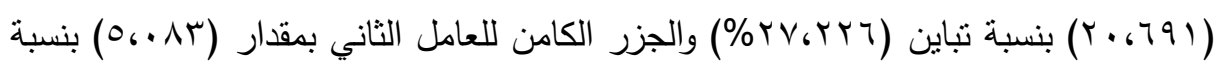

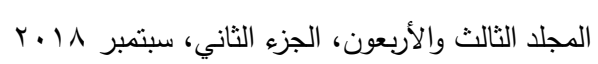




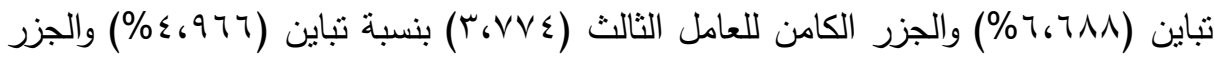

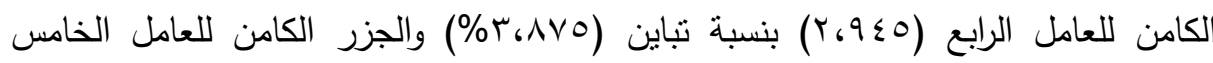

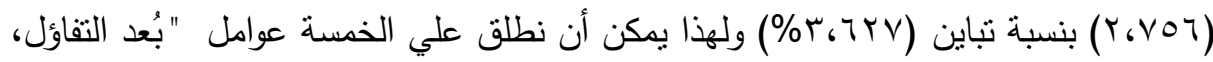

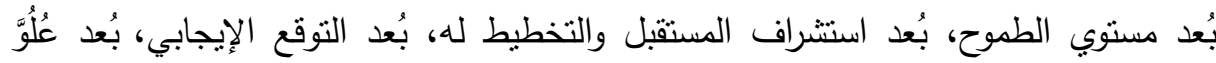

ثبات المقاس: وقام الباحثون بالتأكد من ثبات المقياس كالتالي: 1- ثبات الإعادة: وتم تطبيق

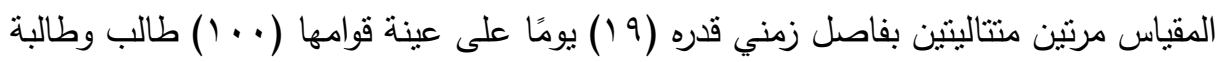

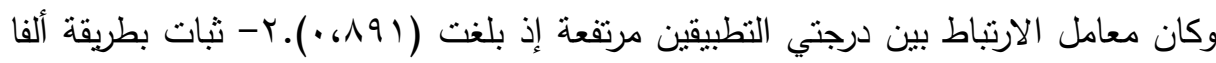

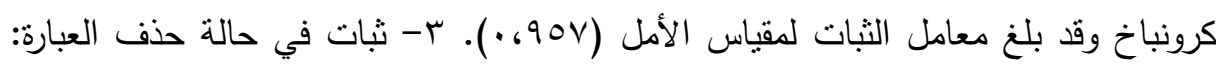

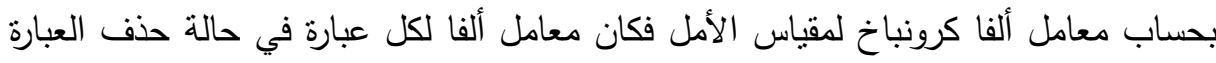

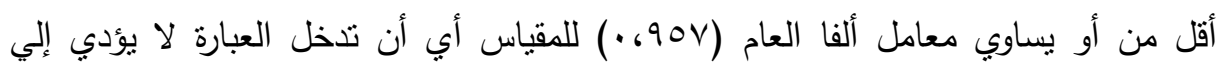

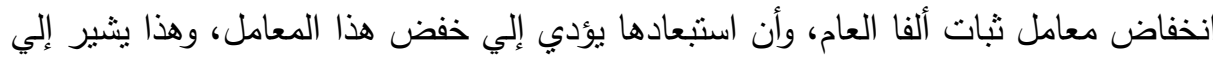
أن جميع العبارات ثابتة. ع- حساب معامل الثبات بطريقة التجزئة النصفية لـ سبيرمانبراون بتقسيم عبارات المقياس إلي عبارات فردية وعبارات زوجية وكانت النتائج للأعداد الفردية هو (بr94، ·) وهو معامل مرتفع ودال إحصائيا، ومعامل ارتباط ألفا كرونباخ بطريقة التجزئة النصفية للأعداد الزوجية هو (10، وهو ، .) وهو معامل مرتفع ودال إحصائيا، وأظهرت النتائج أن

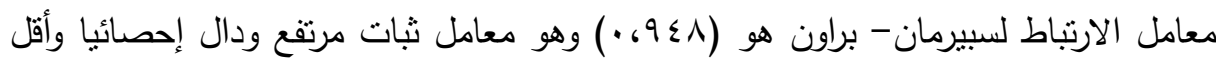

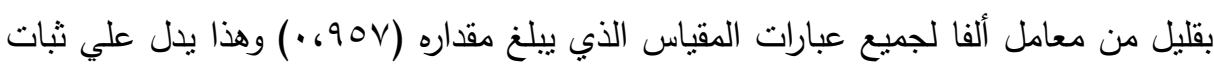
المقياس. رابعاً: مقياس المهارات الثخصية "إعداد الباحثين" حيث قاموا بتقنين المقياس كالتالي: صدق المقياس: 1- صدق المحكمين: تم التحقق من صدق المقياس عن طريق عرضه علي

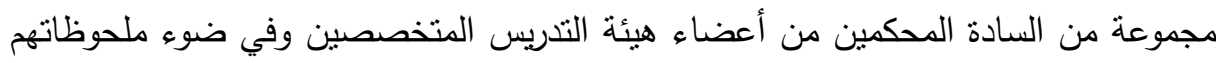

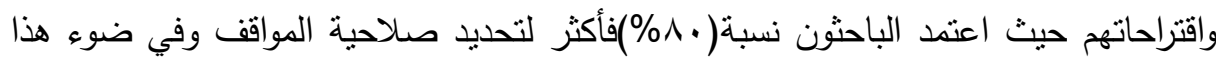
المؤشر تم استبعاد(ب)موقف، وإجراء التعديلات فأصبح المقياس في صورته النهائية يشمل فئرل 


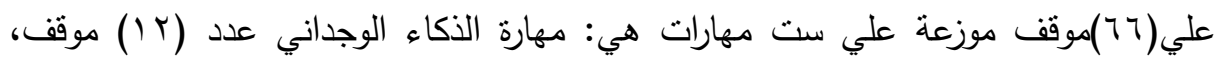

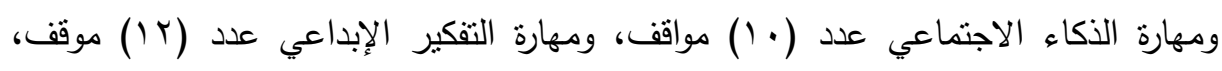

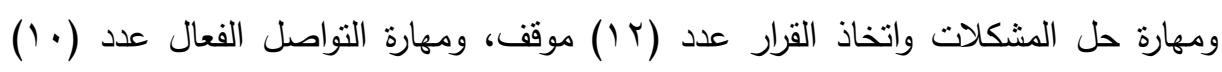

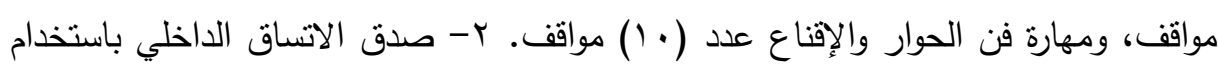

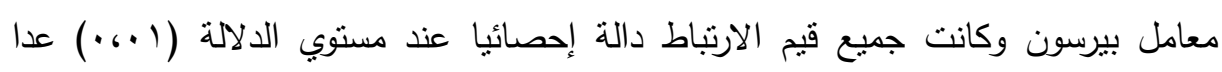

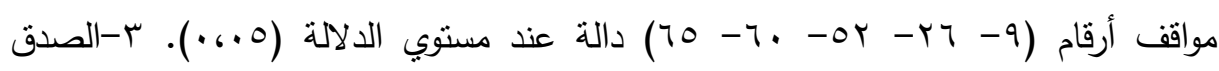
العاملي حيث نم إجراء التحليل العاملي لعدد (77) موقف يمثلون مواقف المقياس، وأظهرت النتائج أن جميع المواقف لم تقل أي قيمة عن (0، ، ) بهذا تكون جميع المواقف دالة إحصائياً،

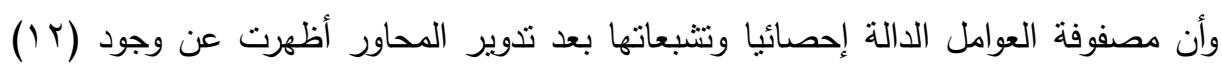

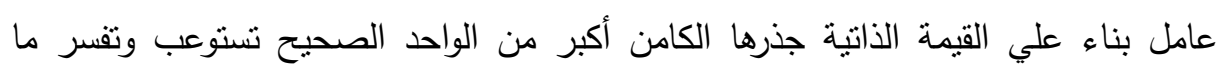

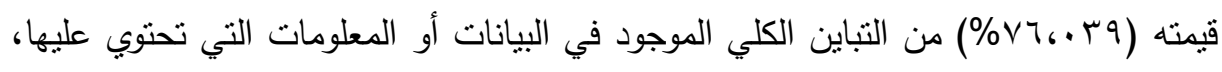
ونلاحظ أن نسبة التفسير أو القوة التفسيرية تختلف من عامل لآخر فقد حاز العامل الأول

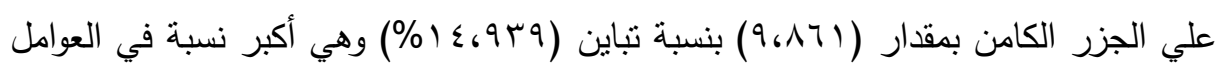

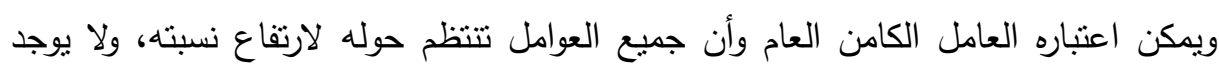
تتبعات لأي موقف من المواقف تقل عن (r، ·) لهذا تم الإبقاء علي جميع المواقف كما تركزت العوامل في ستة هي أعلي جزر كامن بعد تدوير المحاور وترتبط بمعاملات ارتباط مرتفعة مع المواقف وتم حذف العوامل التي لم يتتبع عليها ثلاث مواقف علي اعلي الأقل أو مواقفها متشبعة علي العوامل الستة بنسبة أكبر طبقا لمحك كايزر ونلاحظ أن الجزر الكامن للعامل

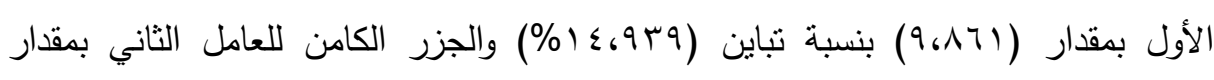

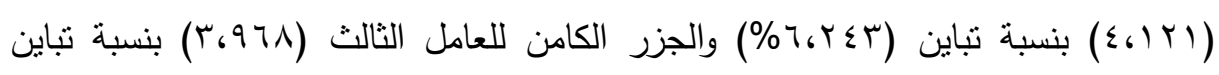

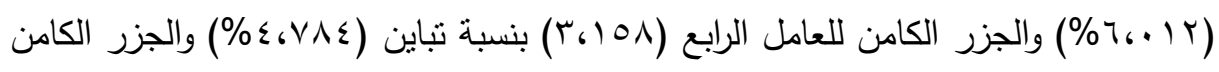

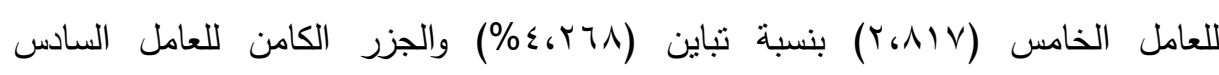

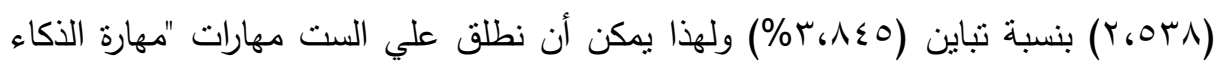

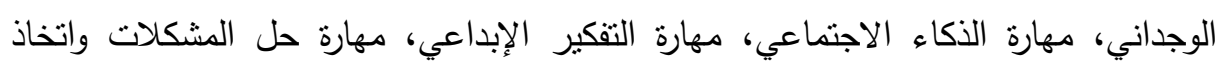
القرار، مهارة التواصل الفعال، مهارة فن الحوار والإقناع".

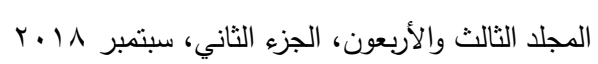


ثبات المقاس: وقام الباحثون بالتأكد من ثنات المقياس كالتالي: 1- ثبات الإعادة: وتم تطبيق

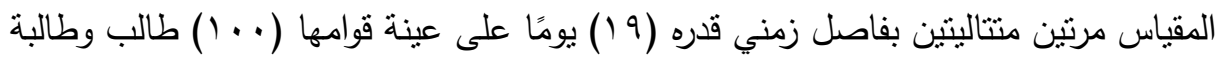

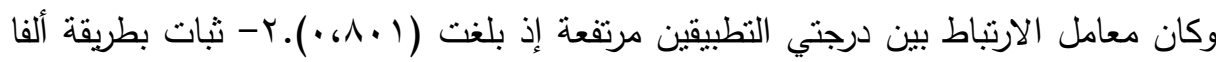

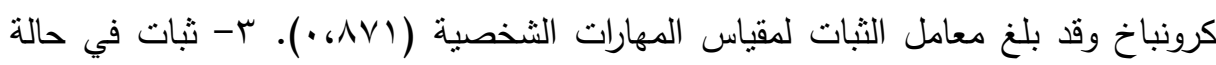

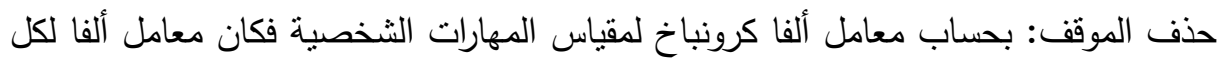

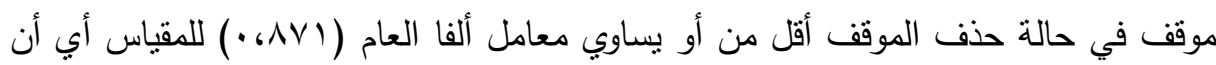

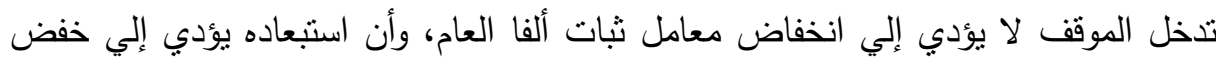
هذا المعامل، وهذا يشير إلي أن جميع المواقف ثابتة. ع - حساب معامل الثبات بطات بلثريقة

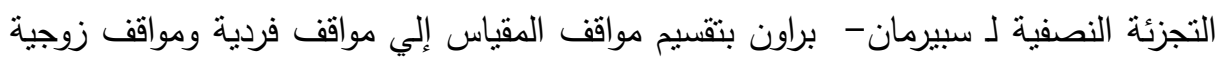

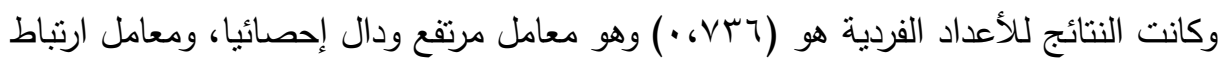

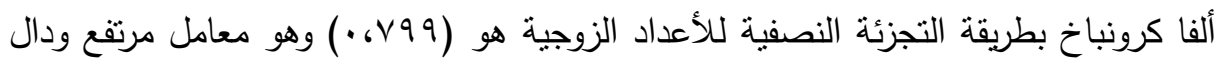

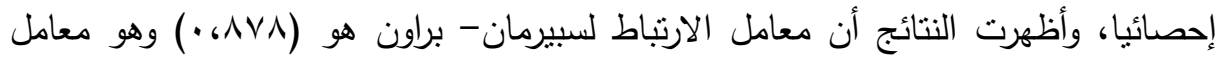

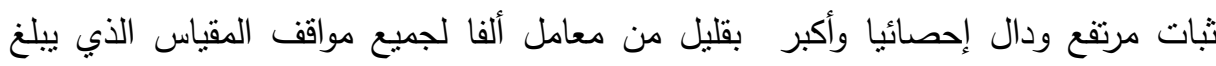
مقداره (AVI، · ) وهذا يدل علي ثبات المقياس.

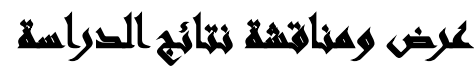

عرض نتائج الفرض الأول ومناقشتها: توجد فروق دالة إحصائية في أبعاد الصمود النفسي (الكفاءة الثخصية- الكفاءة الأسرية- الكفاءة الاجتماعية) والدرجة الكلية للمقياس تعزي إلي الحالة الزوجية بين الأبوين (قائمة- غير قائمة) لدي المتفوقين بالمرحلة الثانوية العامة. وللتحقق من صحة الفرض نم استخدام اختبار (ت) لإيجاد دلالة الفروق والجدول التالي رقم (Y) يلخص هذه النتائج: 


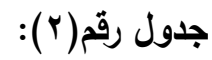

\begin{tabular}{|c|c|c|c|c|c|c|}
\hline \multirow{2}{*}{ الدلالة الدالة } & \multirow{2}{*}{ قيمة } & \multicolumn{2}{|c|}{ غير قائمة } & \multicolumn{2}{|c|}{ قائمة } & \multirow{2}{*}{ أبعاد الصمود النفسىى الأبوين بين } \\
\hline & & $\varepsilon$ & r & $\varepsilon$ & r & \\
\hline$\cdot 6 \cdot \varepsilon$ & $1.9 \wedge 1$ & $7, \wedge \mu$ & AT.VI & 1.611 & 19.97 & بعد الكفاءة الشخصية \\
\hline .6 .0 & 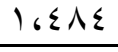 & $V_{6} \leqslant 1$ & $0 \leq 6 . \leqslant$ & $V_{6} 7 \mathrm{~V}$ & 00691 & بعد الكفاءة الأسرية \\
\hline .6 .1 & $r_{6} \varepsilon r T$ & $V_{6} \wedge \mathrm{Ar}$ & $7 \leqslant .07$ & $\Lambda_{6} V V$ & $71_{6} .9$ & بعد الكفاءة الاجتماعية \\
\hline $.6 . Y$ & TGYMI & $11.9 \mathrm{~V}$ & T.0.Mr & Tr.TT & YIT.97 & الدرجة الكلية للمقباس \\
\hline
\end{tabular}

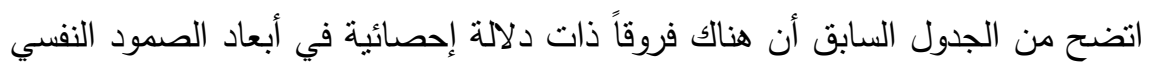

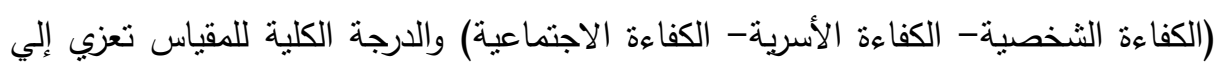

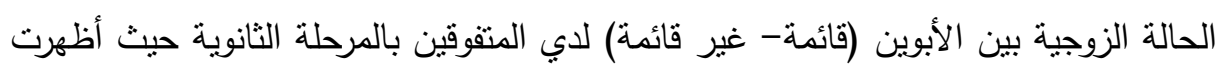

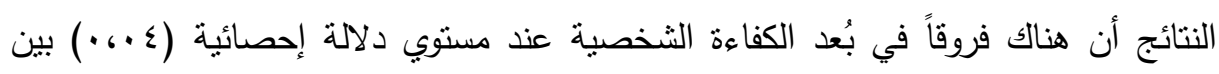

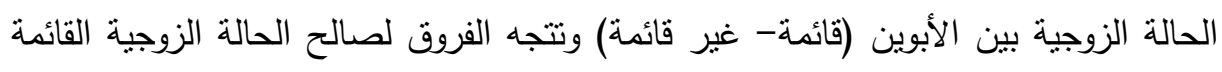
بين الأبوين حيث إن متوسطها الحسابي (97،97) وهو الأعلى، وتوجد فروق في بُعد الكفاءة الأونة

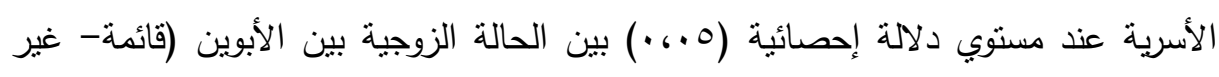

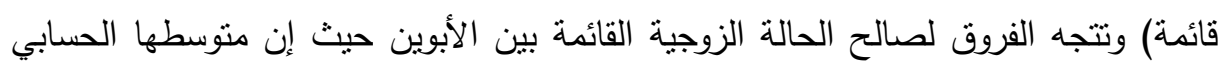

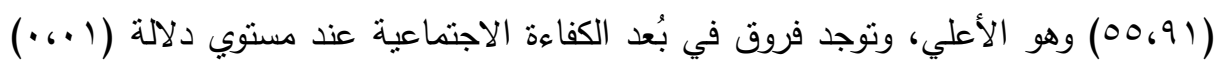

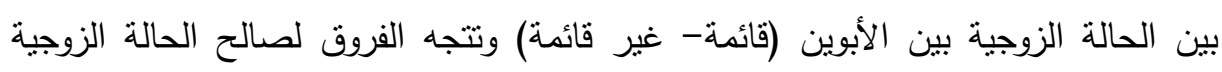

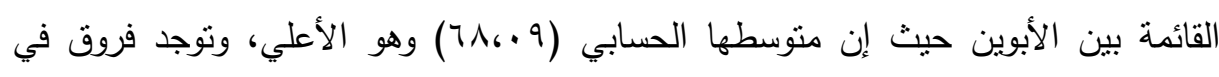

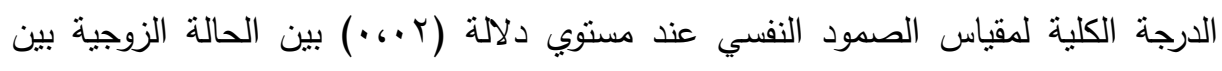

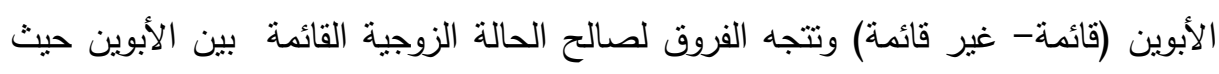

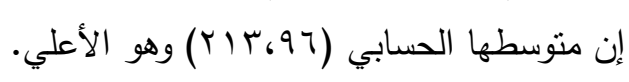

مناقثة نتيجة الفرض الأول: أظهرت نتيجة الفرض الأول أن هناك فروف الاعليطي دالة إحصائياً في

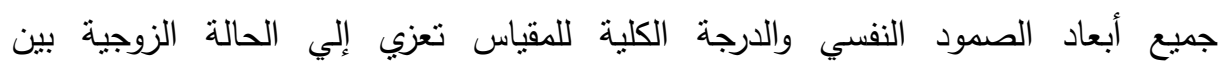

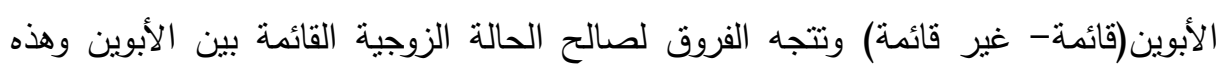

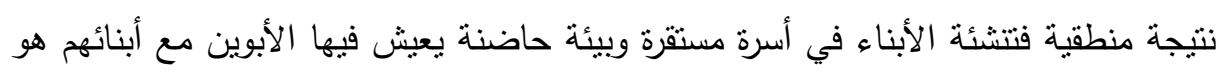

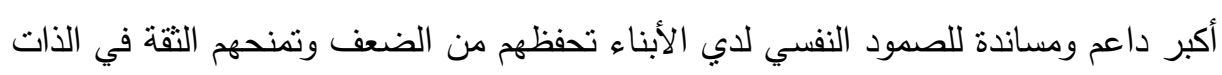

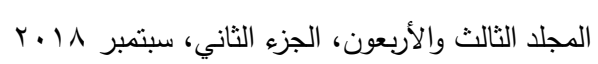


والقدرة علي الصمود النفسي. واتفقت هذه النتيجة مع دراسة ويلز Wells (•(ب) حيث

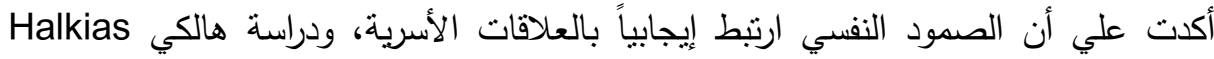

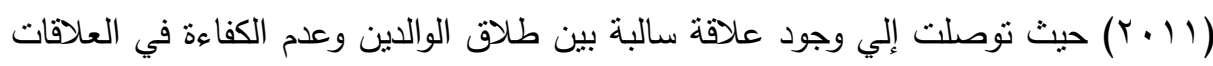

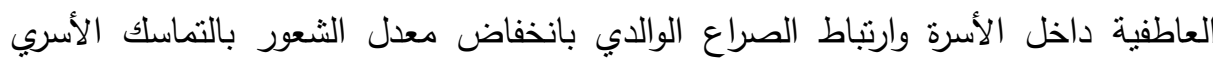
والصمود النفسي، ودراسة أروكياريج وآخرون (Arokiaraj et al. 2011) التي توصلت إلي التباطي وجود علاقة موجبة بين الصمود النفسي والتكيف والتماسك الأسري أب أن الصمود يرتفع في

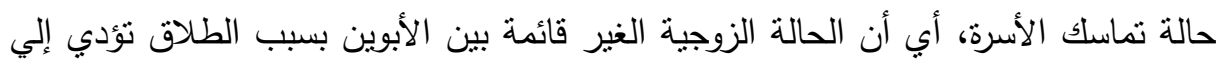

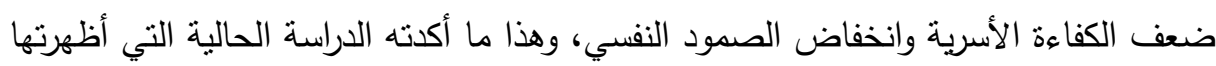

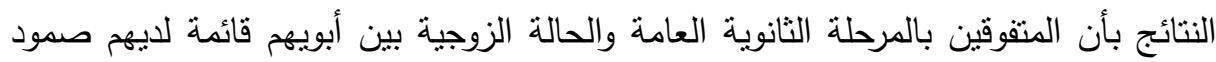

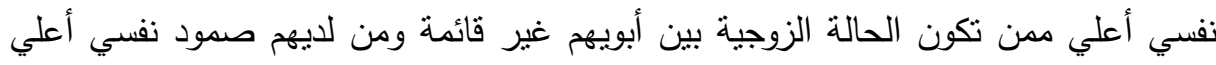

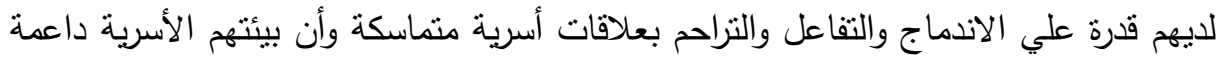

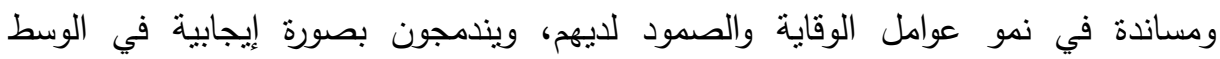

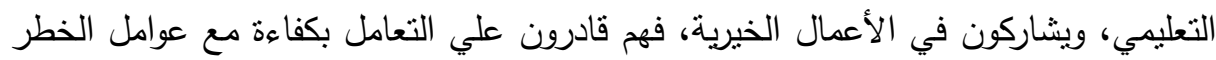
المختلفة. وارتفاع عوامل الحماية والوقاية، التي تتكلت لديهم من خلال كفاءتهم الثخصية، وتتشئتهم الأسرية، والمساندة الاجتماعية. ويجب تقديم البرامج الانتقائية الموجهة للأفراد الذين

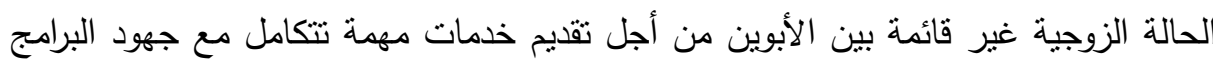
العامة خاصة إذا كانت المحنة التي تعرضوا لها شائعة في المجتمع (الطلاق)؛ لأن البرامج لتهن الانتقائية تبني موارد لتحسين التوافق الفعال لمحن معينة مثل مهارات المواجهة اللازمة لمعالجة التحديات التي تفرضها المحن لدي الأفراد في حالة الطلاق، أو موت أحد الوالدين،

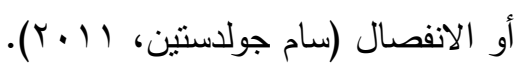
عرض نتائج الفرض الثاني ومناقثتها: توجد فروق دالة إحصائية في أبعاد الأمل (التفاؤل - مستوبي الطموح - استشراف المستقبل والتخطيط له- التوقع الإيجابي - عُلُوَّ الهمَّة) تعزي إلي الحالة الزوجية بين الأبوين (قائمة- غير قائمة) لدي المتفوقين بالمرحلة

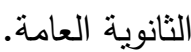


وللتحقق من صحة الفرض نم استخدام اختبار (ت) لإيجاد دلالة الفروق والجدول التالي

\begin{tabular}{|c|c|c|c|c|c|c|}
\hline \multirow[b]{2}{*}{ 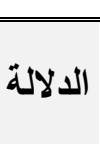 } & \multirow{2}{*}{ قتيمة } & \multicolumn{2}{|c|}{ غير قائمة } & \multicolumn{2}{|c|}{ قائمة } & \multirow{2}{*}{ عاد الأمل الحالة الزوجية ألأبوين } \\
\hline & & $\varepsilon$ & b & $\varepsilon$ & b & \\
\hline $.6 \mathrm{~A}$ & Kזו, & r. 69 & $\leqslant 96 \leqslant 7$ & 1.7T & $\sum q_{6} Y \wedge$ & بُبُعد التفاؤل \\
\hline .67 & $\cdot 6 \leqslant \leqslant \leqslant$ & $7 ، \& 1$ & $7 \pi, 07$ & 1,09 & $\left.7 \varepsilon_{6}\right) \wedge$ & بُعد مستوي الطموح \\
\hline . $\ldots 1$ & r.T7q & $0, \leqslant 7$ & $E Y_{G} T V$ & $T, r T$ & $\varepsilon 0, V T$ & بُعد استتراف المستقبل \\
\hline .6 .0 & 1 (6N1 & $r(q)$ & $r_{V_{6} \wedge \Lambda}$ & $7 . Y)$ & 19617 & بُعد التوقع الإيجابي \\
\hline .6 .0 & $Y_{6} V \cdot T$ & $V_{6} \cdot 1$ & $\{0,07$ & T.AT & $\varepsilon V_{6} 0 \mathrm{Or}$ & بُعد عُلوَّ الهمَّة \\
\hline .6 .0 & r.97. & Yr.AV & $r r \Lambda_{6} \wedge q$ & MYG & $r \leqslant 0, \wedge 9$ & الدرجة الكلية للمقياس \\
\hline
\end{tabular}

اتضح من الجدول السابق أنه لا توجد فروق ذات دلالة إحصائية لدي المتئية بالمرحلة الثانوية في بُعد التفاؤل وبُعد مستوي الطموح تعزي إلي الحالة الزوجية بين الأبوين

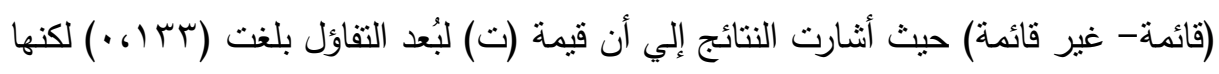

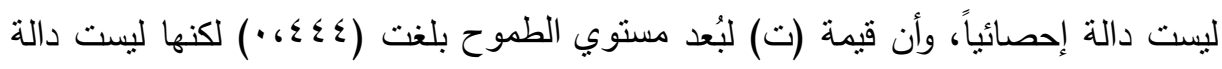
إحصائياً.

ولكن بُعد استشراف المستقبل والتخطيط له أظهرت النتائج وجود فروق ذات دلالة إحصائية عند مستوي دلالة إحصائية بلغت (1 (..، .) بين المتفوقين بالمرحلة الثانوية تعزي

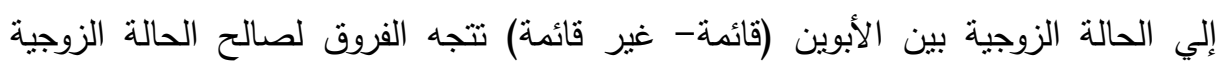

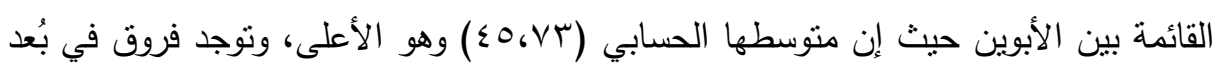

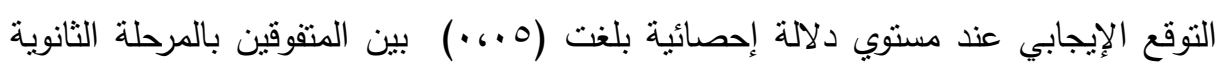

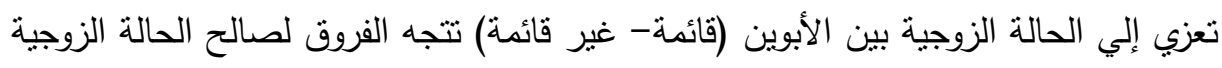

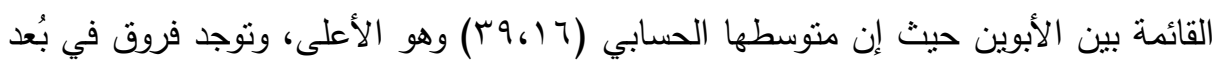

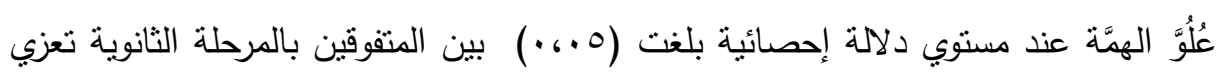

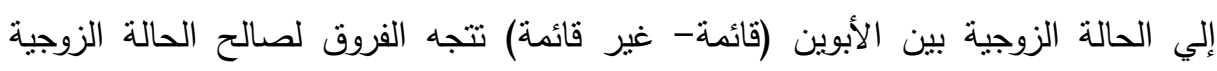

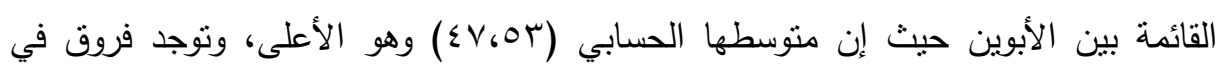

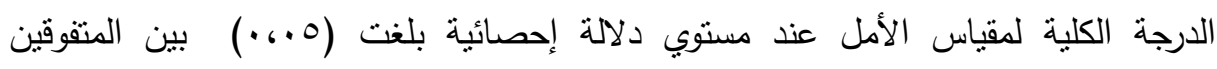

$$
\text { المجلد الثالث والأربعون، الجزء الثاني، سبتمبر 11 ب r }
$$


بالمرحلة الثانوية تعزي إلي الحالة الزوجية بين الأبوين (قائمة- غير قائمة) تتجه الفروق

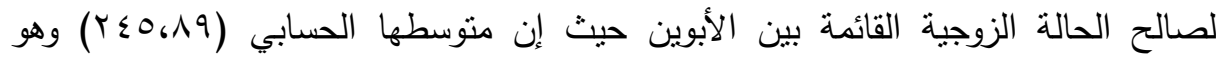

مناقشة نتيجة الفرض الثاني: أظهرت نتيجة الفرض الثاني لا نوجد فروق ذات دلالة

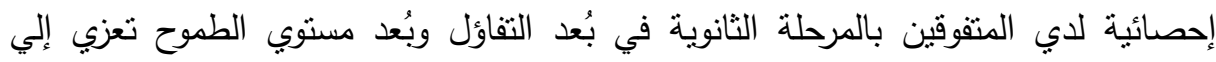

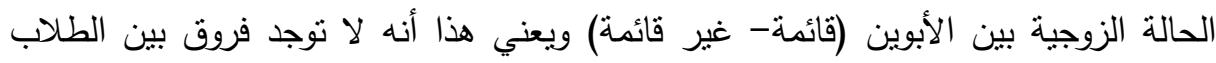
المتفوقين بالمرحلة الثانوية بسبب فقد أحد الوالدين بطلاق أو انفصال أو وفاة أو غيره في بعض أبعاد الأمل هما بُعد التفاؤل و بُعد مستوي الطموح وهذه نتيجة منطقية لكون عينة

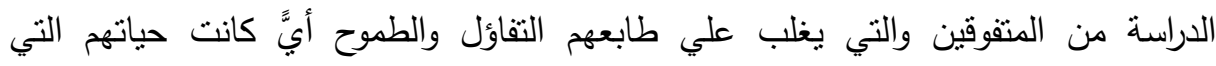

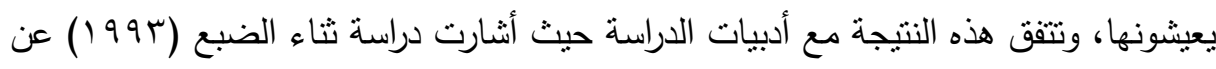
تميز المتفوقين في مستوى الطموح. ولكن نوجد فروق ذات دلالة إحصائية في باقي أبعاد

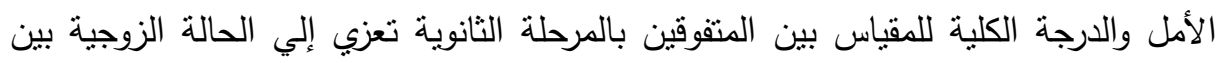

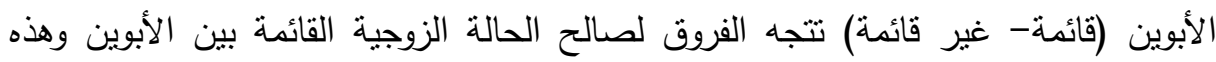

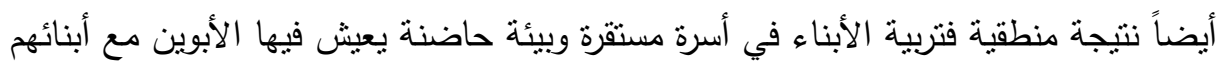
هو أكبر داعم ومساندة لبث روح الأمل لدي الأبناء تدفعهم إلي استتراف المستقبل وتحفزهم

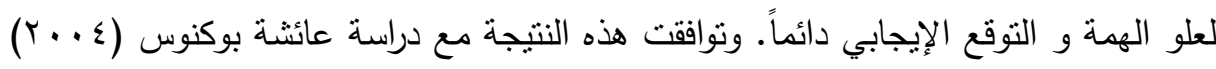

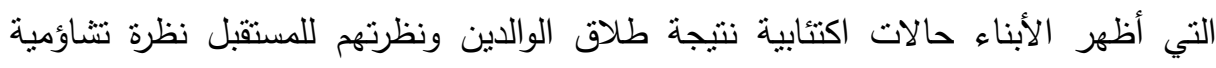
اتسمت بفقدان الأمل وهذا ما نوصلت إليه الدراسة الحالية أن المتفوقين بالمرحلة الثانوية

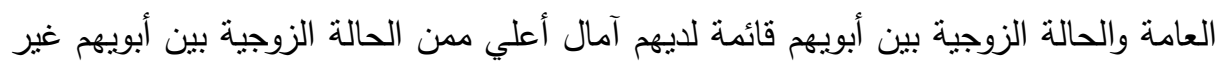

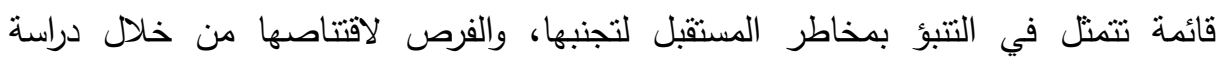

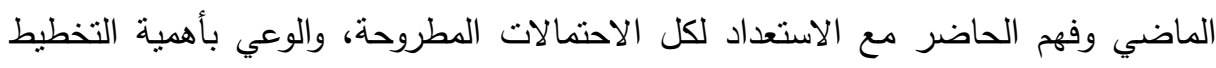
للمستقبل بتحديد الأهداف في ضوء الإمكانيات المنتيسرة الحالية والمستقبلية، وترتيب الأفكار

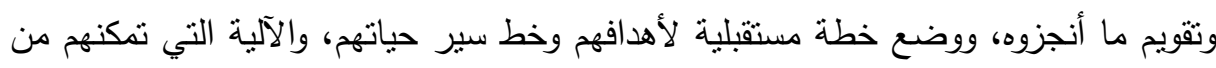

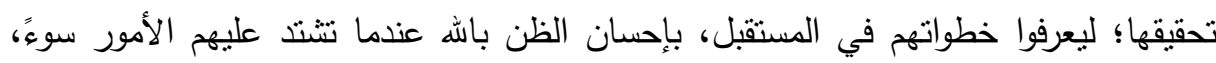


ويجدوا صعوبة في تحقيق أهدافهم، فيمتلئ قلبهم ثقة ويقين ذانياً بأن الأمور ستكون أحسن في المستقبل، ويستطيعوا تجاوزها، لتحقيق الآمال، وطلب معالي الأمور، والمراتب المبات السامية، بإصرار وعزيمة، والتزفع عن الصغائر والدنايا، لإنجاز أهدافهم في الحياة. عرض نتائج الفرض الثالث ومناقشتها: توجد فروق دالة إحصائياً في المهارات الثخصية (الذكاء الوجداني - الذكاء الاجتماعي - التفكير الإبداعي - حل الشكلات واتخاذ

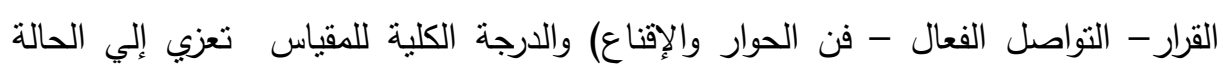

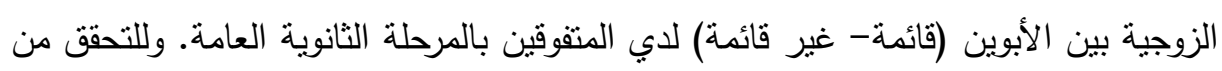

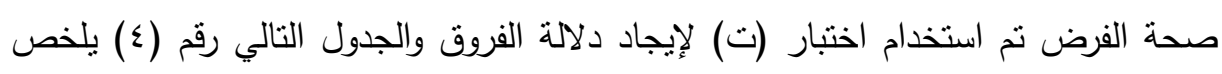

\begin{tabular}{|c|c|c|c|c|c|c|}
\hline \multirow{2}{*}{ 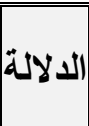 } & \multirow{2}{*}{ قَتمة } & \multicolumn{2}{|c|}{ غيز قُائمة } & \multicolumn{2}{|c|}{ قائمة } & \multirow{2}{*}{ المهارات الشخصية الحالة الزوجية بين } \\
\hline & & $\varepsilon$ & p & $\varepsilon$ & p & \\
\hline.,$T$ & $16.9 \leq$ & T.9 & ¿1، $6 \varepsilon$ & 0,111 & $\varepsilon \cdot .01$ & الذكاء الوجداني \\
\hline .60 & $.60 Y 7$ & 0,57 & rr.7T & r.VV & $r \varepsilon_{6} \cdot r$ & الذكاء الاجتماعي \\
\hline$\cdot .6 \cdot Y$ & Y.YYT & $r .90$ & 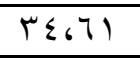 & $\varepsilon 617$ & $r r_{6} \cdot T$ & التقكير الإبداعي \\
\hline$\cdot 6 \cdot$ & $r_{6} \Sigma \cdot V$ & $7, \wedge V$ & rV.10 & $\{67)$ & 19617 & حل المشكلات واتخاذ \\
\hline .69 & $.6 .0 \mathrm{~V}$ & $0 . \leqslant V$ & rr.AI & $\varepsilon 690$ & rY.VT & التواصل الفعال \\
\hline .6 .0 & T.TAV & 0,17 & rr,q) & r.TV & Mr.qs & فن الحوار والإقناع \\
\hline $.6 \mathrm{~V}$ & $.6 \mathrm{YON}$ & TV.OT & YIY,07 & 196.0 & YIT، & الدرجة الكلية للمقياس \\
\hline
\end{tabular}

اتضح من الجدول السابق أنه لا توجد فروق ذات دلالة إحصائية لدي المتقوقين بالمرحلة الثانوية في المهارات الثخصية (الذكاء الوجداني- الذكاء الاجتماعي- التواصل الفعال) والدرجة الكلية للمقياس تعزي إلي الحالة الزوجية بين الأبوين (قائمة- غير قائمة)

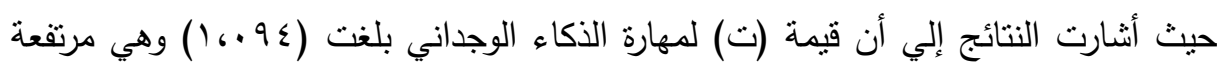

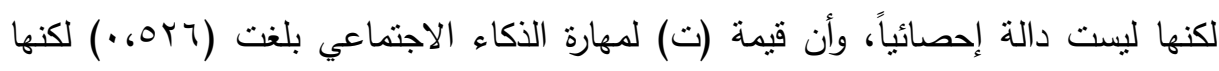

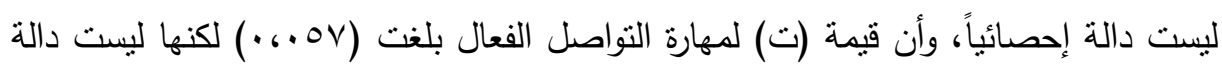

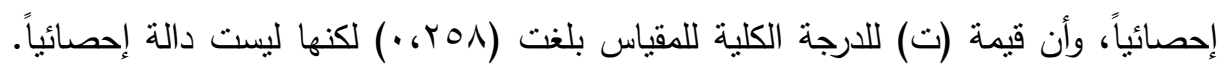

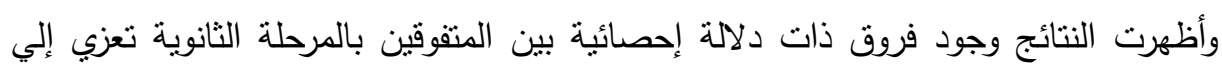

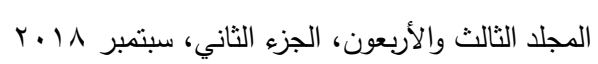


الحالة الزوجية بين الأبوين (قائمة- غير قائمة)، في مهارة التفكير الإبداعي عند مستوي دلالة

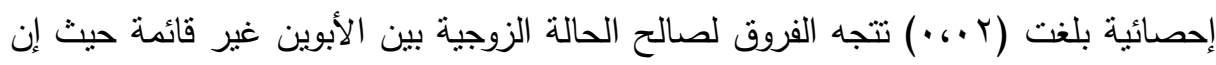

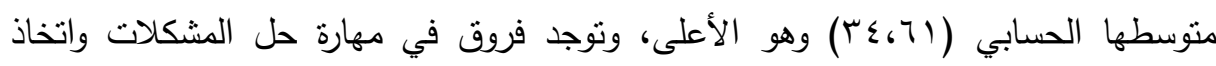

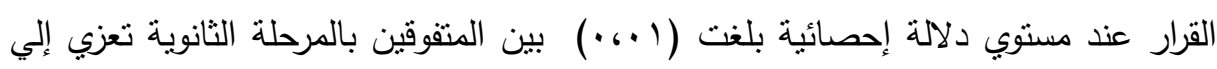

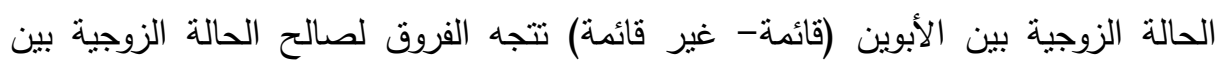

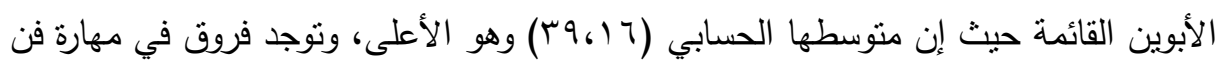
الحوار والإقناع عند مستوي دلالة إحصائية بلغت (0.، •) بين المتفوقين بالمرحلة الثانوية الإية

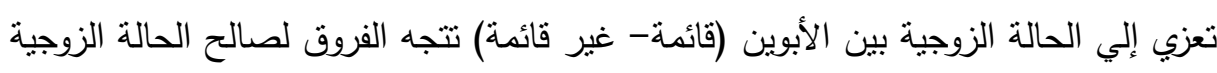

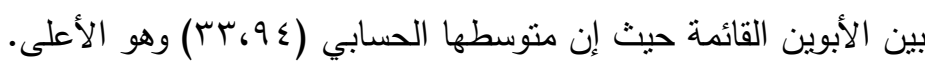

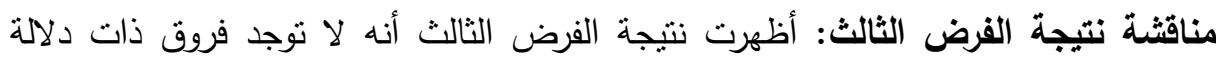
إحصائية لدي المتفوقين بالمرحلة الثانوية في المهارات الثخصية (الذكاء الوجداني- الذكاء الاجتماعي- التواصل الفعال) والدرجة الكلية للمقياس تعزي إلي الحالة الزوجية بين الأبوين (قائمة- غير قائمة) ويعني هذا أنه لا توجد فروق بين الطلاب المتفوقين بالمرحلة الثانوية بسبب فقد أحد الوالدين بطلاق أو انفصال أو وفاة أو غيره في بعض الون المهارات الثخصية كمهارة الذكاء الوجداني ومهارة الذكاء الاجتماعي ومهارة التواصل الفعال والدرجة الكلية للمقياس، وهذه نتيجة منطقية لكون عينة الدراسة من المتفوقين والتي يغلب علي طابعهم التميز

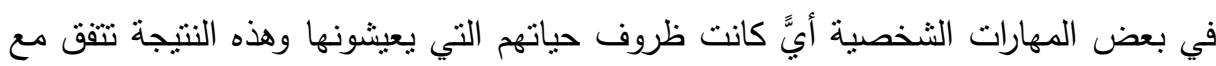
أدبيات الدراسة، حيث توصلت دراسة زينب عبدالرحمن القاضي (910 (1) تميز المتقوقين

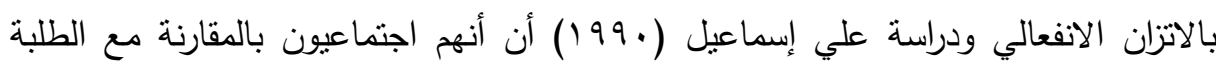

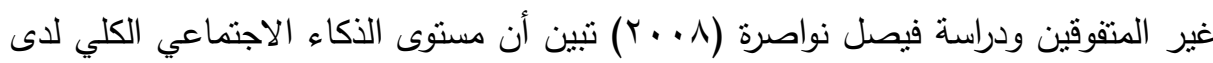
الطلبة المتفوقين مرتفعاً. وأظهرت النتائج وجود فروق ذات دلالة إحصائية بين المتفوقين

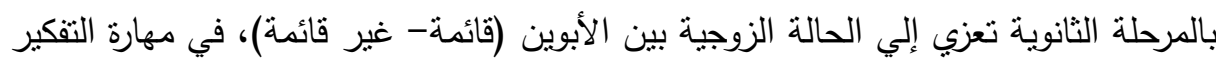

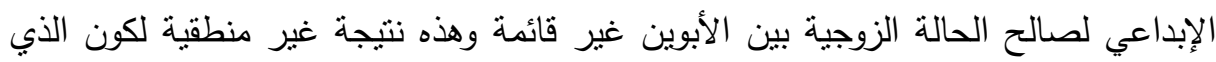

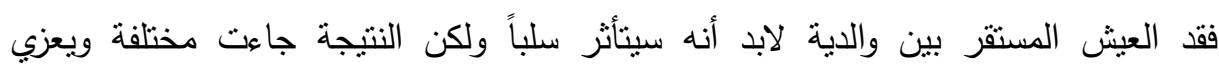


الباحثون أن فقد أحد الوالدين بطلاق أو وفاة أو غيره وانفصال العلاقة بين الأبوين لأي سبب

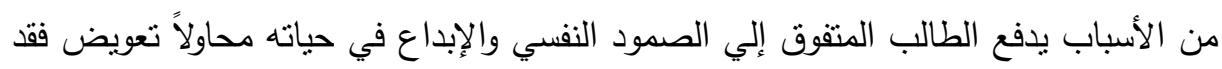

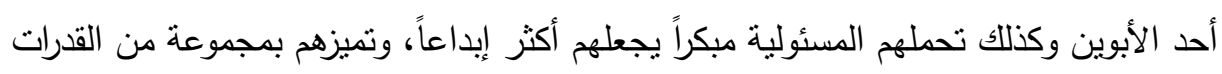

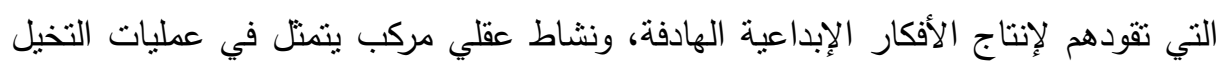
والاستبصار والاكتشاف، ويتميز بالثمولية والتعقيد والطلاقة والأصالة والمرونة. وأظهرت

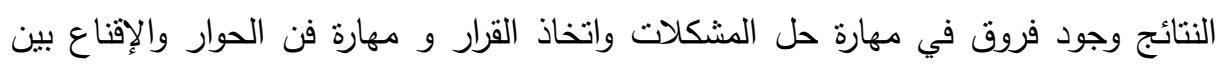

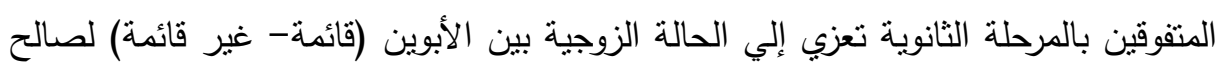
الحالة الزوجية بين الأبوين القائمة وهذه نتيجة منطقية تتفق مع أدبيات التوجه النظري للإراسة.

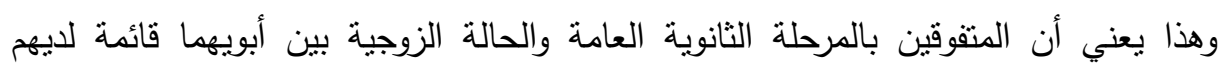

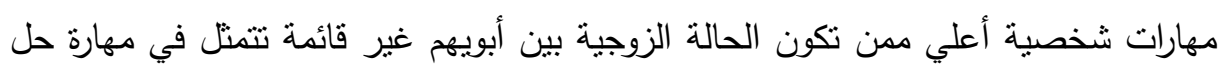
المشكلات واتخاذ القرار بعملية عقلية معرفية سلوكية منظمة، يحاولون من خلالها تحديد

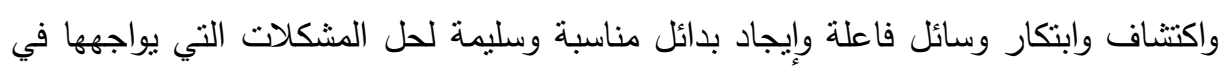
حياته اليومية، ومهارة فن الحوار والإقناع بعملية تبادل الحديث أو الكلمات بينهم والآخرين

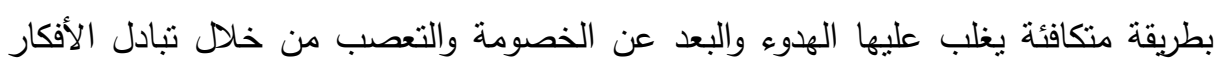

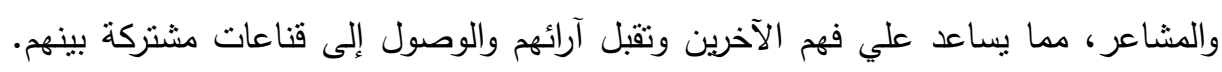

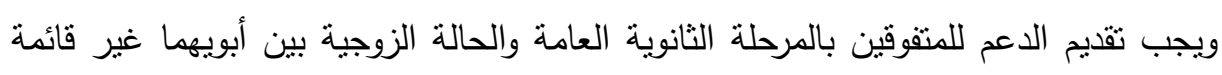

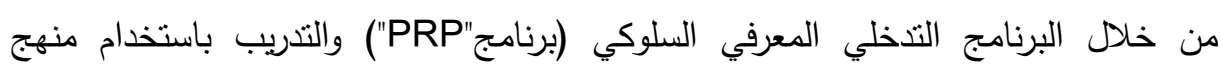

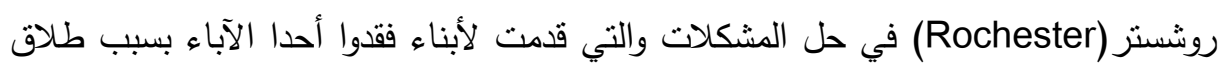

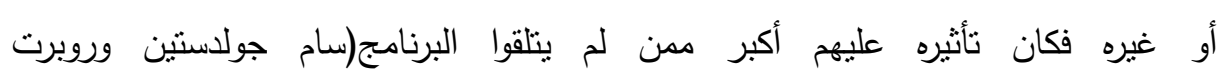

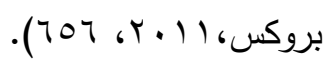




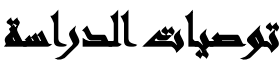

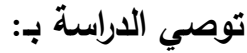

ا- نتمية الوعي بأبعاد فقدان العلاقة بين الوالدين لطلاب المرحلة الثانوية، وبيان أثر ذلك على اتجاهات الطلاب وانتماءاتهم وآمالهم المستقبلية، وبناء آليات معالجة هذه الأزمة في لياتي المؤسسات المعنية بتتشئة المراهقين ورعايتهم وتتمية مهارتهم الثخصية. ץ- تتمية الوعي بالتحديات التي تواجه طلاب المرحلة الثانوية، والتي تتطلب إدخال تغييرات هيكلية في مختلف مجالات المجتمع الاقتصادية والسياسية والثقافية والاجتماعية. r- توفير فرص مجتمعية تتيح للأفراد الوصول إلى الموارد البيئية والثخصية التي تطور قدرتهم على الصمود النفسي بطرق مجدية، وتقتح لهم آمال مستقبلية.

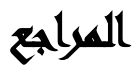

آمال صادق وفؤاد أبو حطب( ـ99 (1)): علم النفس النزبوي، الأنجلو المصرية.

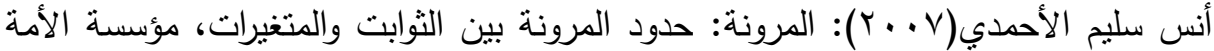

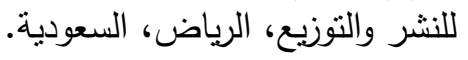

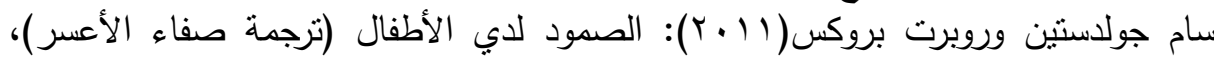
المركز القومي للترجمة، القاهرة.

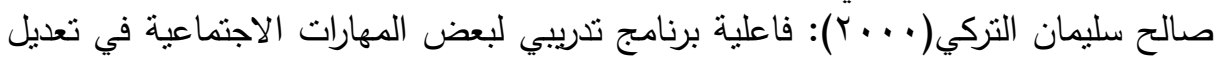

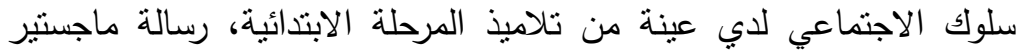

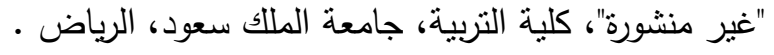
صفاء الأعسر: الصمود من منظور علم النفس الإيجابي، المجلة المصرية للإية للإراسات النفسية،

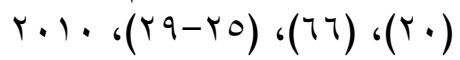

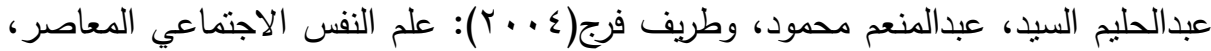
أيتراك للطباعة والنشر ، القاهرة.

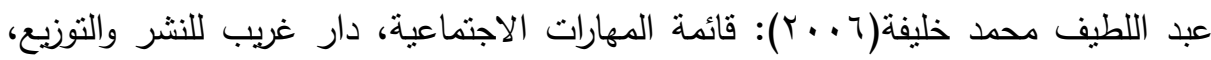

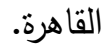

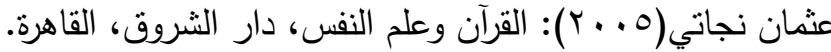

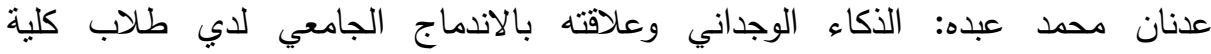

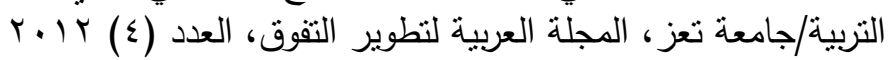


فضل ابراهيم عبد الصمد: الثعور بالأمل والرغبة في التحكم لدي عينة من طلاب الدراسات

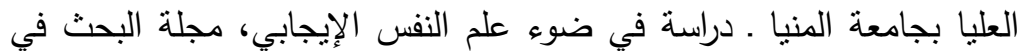

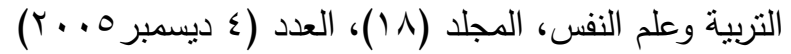

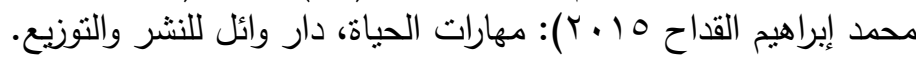

Ashleigh Lauren Mutcher(2011): Hope-Focused Strategies For Counsellors, Faculty oF Education, University of Lethbridge, Alberta.

(APA)(2000): The road to resilience Psychologist, Washington, Discovery Health Chanel, American Psychologist, 56(3), 227-238.

Averill, Catlin\& Chon(1990): Rules of hope. New York:SpringerVerlag.

Boisvert, J. (2001): The Relationship between Level of Hope and Ways of Coping for Women with Eating Disorders.MA,University of Regina.

Gayles, J. (2005): Playing the game and playing the price: Academic resilience among three high- achieving African American Males, Anthropology and Education Quarterly, 36, 3, 250264.

Hart, K\&Sasso, T(2011): Mapping the contours of contemporary positive psychology, candian psychology, 52(2), 82-92.

Horner,S\& Rew,L (2003): Personal strengths of homeless adolescents living in high-risk environment. Advances in Nursing science,26,2,90-101.

Maginness, A. (2007): The development of Resilience- A Model. Ph. D. Thesis. University of Canterbury.

Martha Chamodraka(2008):Hope Development in Psychotherapy, Department of Educational, Counselling Psychology, McGill University,

Peterson,\& Byron,(2008): Exploring the role of hope in Job Performance: Results from four studies, Journal of Organizational Behavior, VOI 29.

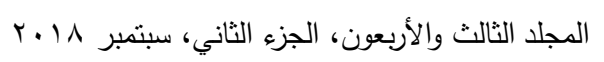


Snyder, Rand, \& Sigmon(2002): Hope theory:A member of the positive psychology family. In Snyder \& Lopez (Eds.), Handbook ofpositive psychology (pp. 257-276). New York: Oxford University Press.

\title{
RELATIONSHIP OF PSYCHOLOGICAL WITHSTAND AND HOPE WITH SOME PERSONAL SKILLS OF OUTSTANDING STUDENTS IN SECONDARY STAGE
}

Mohamed, T. A. ${ }^{(1)}$; Al-Atiq, A. M. ${ }^{(2)}$ and Mahmoud, A. E. ${ }^{(3)}$ 1) The Institute of Environmental Studies \& Research-Ain Shams University 2) National Center for Educational StudiesEvaluation

\begin{abstract}
The study aimed to identify the differences between the grades of the students of the sample on psychological resilience, hope, and some personal skills attributed to the marital status between the parents (list non-existent) of the high school graduates. The sample of the study was (304) students between the ages of (16-18 years). Study Approach: The present study, during the stages of its preparation and implementation, adopted the descriptive (analytical descriptive) approach to the subject and objectives of the study. Study hypotheses:1-There are statistical differences in the dimensions of psychological resilience (personal efficiency - family efficiency - social efficiency) and the total score of the measure to the marital status of the parents (list - non-existent) of the high school graduates. 2-There are statistical differences in the dimensions of hope (optimism - the level of ambition - the prospect of the future and planning - positive expectation - high intensity) and the overall degree of the measure attributed to the marital status between parents (list - non-existent) of the high school graduates. 3-There are 356

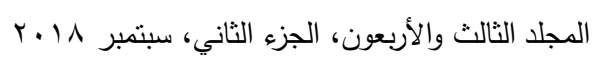




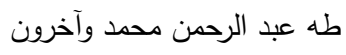

statistical differences in the personal skills (emotional intelligence social intelligence - creative thinking - problem solving and decision making - effective communication - the art of dialogue and persuasion) and the total score of the measure attributed to the marital status between parents (list - non-existent) the public. The researcher used the descriptive analytical method and the use of statistical methods on the program (spss). The results were as follows:1-There are differences of statistical significance in the dimensions of psychological resilience (personal efficiency - family efficiency - social efficiency) and the total score of the measure to the marital status of the parents (list - nonexistent) in favor of marital status between parents. 2-There are no statistically significant differences among the high school graduates after optimism and after the level of ambition attributed to the marital status between the parents (list - non - existent), and there are differences of statistical significance for the high school graduates in the post - future planning and planning and after the expectation The positive and the high degree of the measure of hope is attributed to the marital status between the parents (list - non-existent) in favor of marital status between parents. 3-There are no statistically significant differences among high school graduates in the personal skills (emotional intelligence - social intelligence - problem solving and decision making - effective communication) and the total score of the measure attributed to the marital status between parents (list - non existent), and there are significant differences Statistics of the high school graduates in the skills of (creative thinking - problem solving and decision-making - the art of dialogue and persuasion) to the marital status between parents (list - non-existent) in favor of marital status between parents in my skills (problem solving and decision-making) and for the marital status that does not exist between parents in the skill of creative thinking. Keywords: Psychological resilience, hope, personal skills, high school graduates.

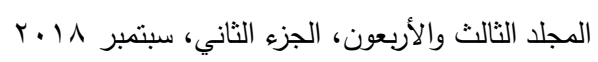

